Optimizing the coupling ratio of seismic resistant HCW systems with shear links

Peer-reviewed author version

DAS, Rajarshi; Zona, Alessandro; VANDOREN, Bram \& DEGEE, Herve (2018)

Optimizing the coupling ratio of seismic resistant HCW systems with shear links. In: JOURNAL OF CONSTRUCTIONAL STEEL RESEARCH, 147, p. 393-407.

DOI: 10.1016/j.jcsr.2018.04.026

Handle: http://hdl.handle.net/1942/26705 


\title{
OPTIMIZING THE COUPLING RATIO OF SEISMIC RESISTANT HCW SYSTEMS WITH SHEAR LINKS
}

\author{
Rajarshi Das ${ }^{1, *}$, Alessandro Zona ${ }^{2}$, Bram Vandoren ${ }^{1}$, Hervé Degée ${ }^{1}$ \\ ${ }^{1}$ Construction Engineering Research Group, Hasselt University, Hasselt, Belgium \\ ${ }^{2}$ School of Architecture and Design, University of Camerino, Ascoli Piceno, Italy
}

\begin{abstract}
This paper investigates through nonlinear static and dynamic analyses the behaviour of a newly introduced steel and concrete hybrid coupled wall (HCW) system made by a single reinforced concrete (RC) wall coupled to steel columns by means of steel links, a structural solution of potential interest for seismic-resistant multi-storey buildings. The considered $\mathrm{HCW}$ is conceived as seismic resistant system where the $\mathrm{RC}$ wall and the steel columns remain undamaged while the seismic energy is dissipated by yielding concentrated in the steel links only. In order to achieve such a desired seismic behaviour, a proper design procedure must be adopted and validated. Accordingly, this study reviews a recently proposed design approach and presents some modifications to further improve the seismic behaviour of the considered HCW system. Case studies are designed using the proposed modified design method as well as its former version. Afterwards, the seismic behaviour of the considered case studies is analysed to identify the optimal degree of coupling between the RC wall and steel columns, also evaluating the influence of the building height and uniform or nonuniform distribution of shear links. The obtained results confirm the improvements of the modified design method proposed in this study and provide support for the selection of the design parameter that influences the most in the seismic behaviour of the innovative HCW system, i.e. the degree of coupling between RC wall and steel columns, controlled by the adopted steel links.
\end{abstract}

Keywords: Steel-concrete hybrid structures; Shear links; Energy dissipation; Seismic design; Coupling Ratio; Seismicresistant structures

\section{INTRODUCTION}

Coupled walls are a very interesting solution for the design of seismic-resistant multi-storey buildings, starting from reinforced concrete (RC) walls coupled by RC beams [1-5] as shown in Fig. 1a to more recent steel and concrete hybrid coupled walls (HCWs) where coupling between RC walls is achieved through steel or steel-concrete composite beams [6-26], (Fig. 1b), which are often organized as structural fuses that can be substituted when damaged. To further improve the combination of the RC wall and steel elements, a new structural configuration for HCW systems (Fig. 1c) was recently proposed, developed and studied using numerical and experimental tools in the European research project INNO-HYCO (INNOvative HYbrid and COmposite steel-concrete structural solutions for building in seismic area [27]). This system consists of a RC shear wall coupled to steel side columns by means of steel links. The RC wall carries almost all the horizontal shear force while the overturning moments are partially resisted by an axial compression-tension couple developed by the two side steel columns rather than by the individual flexural action of the wall alone.

* Corresponding author.

Email address: rajarshi.das@uhasselt.be

Address: Universiteit Hasselt, Campus Diepenbeek, Agoralaan, Gebouw H, B-3590 Diepenbeek, Kantoor B 103 b 
(a)

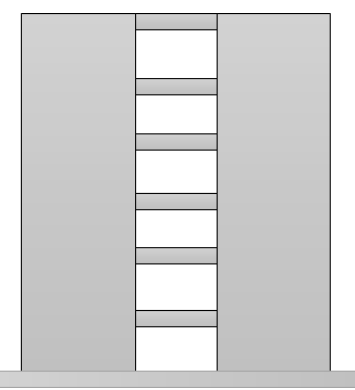

(b)

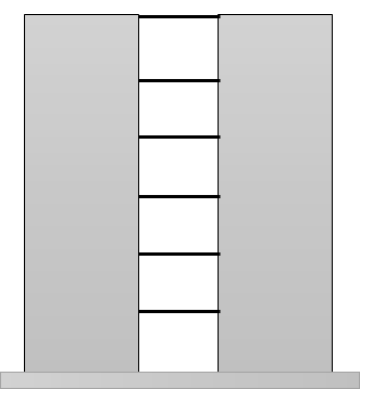

(c)

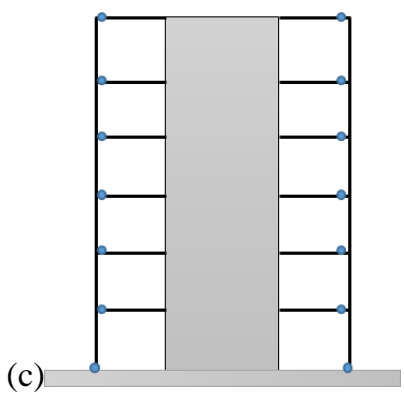

Fig. 1. Examples of: (a) conventional RC coupled shear wall system; (b) conventional hybrid coupled shear wall system; and (c) the proposed coupled wall system made by one wall coupled to two side columns.

The HCW system performances are directly related to the strength and ductility of the links [28]. Well-designed links provide a suitable source of energy dissipation. The ability of a structure to deform inelastically without significant loss of strength generally improves the seismic response by limiting forces in the structural members, lengthening the effective period and providing hysteretic energy dissipation. According to previous researches [29-36], ductile yielding of members in shear prior to flexure represents an effective mechanism of energy dissipation in earthquake resistant structural systems, e.g. eccentrically braced frames. Shear links, i.e. links in which shear dominates the inelastic response, behave as a metallic hysteretic device (fuse) limiting the maximum lateral force that can be transmitted to the non-dissipative structural members and providing significant energy dissipation potential. Hjelmstad and Popov [30], as well as Kasai and Popov [31] demonstrated excellent efficiency regarding both strength and energy dissipation capacity of the shear links through both analytical and experimental studies of the hysteretic response. This particular idea of utilizing shear yielding members as energy dissipation devices gave inspiration to improved structural systems such as disposable knee braced frames by Balendra et al. [37], aluminium shear-links by Rai and Wallace [38], hybrid coupled walls by Harries et al. [39], and proposal for structural rehabilitation by Ghobarah and Elfath [40] as well as energy dissipation devices between the tower shafts by McDaniel et al. [41].

An important parameter characterizing the structural behaviour of coupled systems is the degree of coupling or coupling ratio (CR). For a conventional two-wall coupled system, CR is defined as the proportion of system overturning moment resisted by the coupling action [7],

$$
C R=\frac{L \sum V_{\text {Beam }}}{L \sum V_{\text {Beam }}+\sum M_{W}}
$$

where, $\sum \mathrm{V}_{\text {Beam }}=$ accumulation of coupling beam shears acting on each wall pier; $\mathrm{L}=$ lever arm between the centroids of the wall piers; and $\sum \mathrm{M}_{\mathrm{w}}=$ total overturning moment resisted by the wall piers. Similarly, for INNO-HYCO HCW system considered in this study, the CR is defined as the ratio of the total overturning moment resisted by the two side columns $\left(\mathrm{M}_{\mathrm{c}}\right)$ to the total overturning moment $\left(\mathrm{M}_{\mathrm{c}}+\mathrm{M}_{\mathrm{w}}\right)$ as shown in Eq. 2 .

$$
C R=\frac{M_{c}}{M_{c}+M_{W}}
$$

The coupling beams provide transfer of vertical forces between the $\mathrm{RC}$ wall and the side columns, which creates a coupling action that resists a portion of the total overturning moment induced by the seismic action. A significant number of investigations were carried out for understanding the influence and providing indications on the selection 
of $\mathrm{CR}$ in conventional RC and hybrid coupled systems, e.g. [42-48]. Coupling provided by the presence of a slab coupling two adjacent walls is very low and generally not considered in the design [42]. Harries [43] proposed a practical upper limit of $66 \%$ for the CR of HCWs, whereas El-Tawil and Kuenzli [8] recommended a CR range from 30 to $45 \%$ for an efficient design. Furthermore, Harries and McNeice [45], in a study on RC coupled walls, recommended "grouping" coupling beams and allowing for vertical redistribution of coupling beam forces (similar to the approach allowed in the Canadian A23.3 Concrete Design Standard) in order to minimize demands on the wall piers while continuing to provide coupling action consistent with the expected behaviour of the system. On the other hand, little information is available for the INNO-HYCO HCW system [28] and further research is indeed needed to provide more insight into the relation between adopted CR and attained seismic behaviour.

The objective of this research is to refine the currently available procedure for seismic design of INNO-HYCO HCW systems [28] by enforcing that the steel links are designed as shear critical links in order to improve the expected seismic behaviour. This goal is attained by integrating a mathematically derived relationship between flange thickness, web thickness, flange width, total depth of the link section and link length. The proposed design approach is verified by investigating through nonlinear static and dynamic analyses of the structural response of a number of case studies designed with varying CRs. Moreover, as very little information exists regarding an optimal range of CR for the INNOHYCO HCWs, this present research also aims to search for an the most efficient CR with or without uniform link distribution, its lower and upper limit compatible with the adopted link distribution, as well as the influence of the building height.

\section{DESIGN METHODOLOGY OF THE INNO-HYCO HCW SYSTEMS}

The design procedure proposed in the INNO-HYCO project for innovative HCW systems is followed and modified in the present study to design the coupling links as shear critical elements. Step 1, 2, 3, 5 and 6 are all adopted without any variations from the previous design procedure as suggested by Zona et al [28]. However the newly derived modifications are introduced as step 4.

\section{Step 1: Design of the RC Shear Wall.}

The dimensions of the RC wall are chosen by selecting suitable height-to-length ratio $\mathrm{H}_{\mathrm{w}} / 1_{\mathrm{w}}$ and thickness $b_{w}$. The analyses performed in the INNO-HYCO research project [27, 49] suggested an optimal value of $H_{w} / l_{w}=10$, coming from the need to have a wall able to have sufficient lateral deformability to yield links without significant damage. Values of $\mathrm{H} / \mathrm{Lw}$ smaller than 10 provided designs with too much lateral stiffness to this purpose while values higher than 10 provided excessive lateral deformability causing damage limitation problems. The minimum value of $b_{w}$ should be selected according to the required capacity and to adequately accommodate the connection between wall and steel links. The longitudinal reinforcements are chosen based on Eurocode 8 [50] DCM rules in order to maximize the wall flexural capacity, $M_{w, r d}$ directly determined using conventional nonlinear sectional analysis.

Step 2: Deciding an initial value of the CR.

In order to investigate the sensitivity of the structural response, the CR value is varied in this study to acquire a better insight of the design demands and resulting shear link sections as well as the structural behaviour of the coupling system for various choices of CRs. 
Step 3: Design of the dissipative shear critical steel links.

After CR is chosen, the axial force $N_{c}$ is derived as described in [28]:

$$
N_{c}=\frac{M_{c}}{L_{t o t}}=\frac{C R}{1-C R} \frac{M_{w}}{L_{t o t}}=\frac{C R}{1-C R} \frac{M_{w, R d}}{L_{t o t} \gamma_{w}}
$$

where $M_{c}$ is the moment resisted by the two side columns, $L_{t o t}$ is the length of the RC wall plus twice the link length, $\gamma_{w}$ is a safety coefficient used to limit or possibly avoid damage in the $\mathrm{RC}$ wall by reducing its bending moment capacity [28] and is assumed equal to 1.5. Thus, the shear force demand on the links can be calculated as:

$$
V_{\text {link }, i}=\psi_{i} \frac{N_{c}}{n_{\text {links }}}=\psi_{i} \frac{1}{n_{\text {links }}} \frac{C R}{1-C R} \frac{M_{w, R d}}{L_{\text {tot }} \gamma_{w}}
$$

Where $n_{\text {links }}$ is the no. of links on each side of the RC wall and $\psi_{\mathrm{i}}$ is a distribution coefficient. Two different values of $\psi_{\mathrm{i}}$ are used and compared, namely, uniform distribution (similar sections used throughout all height levels of structure, Eq. 5), and non-uniform distribution (different sections used for different height levels of structure as shown in Eq. 6):

$$
\begin{aligned}
& \psi_{i}=1 \\
& \psi_{i}=\left\{\begin{array}{lr}
1+\frac{2}{3} & z_{i} \leq \frac{N}{3} \\
1 & \frac{N}{3}<z_{i} \leq \frac{2 N}{3} \\
1-\frac{2}{3} & \frac{2 N}{3}<z_{i} \leq N
\end{array}\right.
\end{aligned}
$$

Where, $N$ is the total number of storeys in the structure and $z_{i}$ is a function to denote the chosen storey level. The value of CR, above which design objectives cannot be fulfilled with a uniform distribution of the link sections might be called as the critical limit of CR, which can be determined via a trial and error method. Non-uniform distribution of links must be adopted for CRs above this critical value where 3 different sections are used for 3 different zones (defined as per Eq. 6, i.e. top third, bottom third and central part of the building). Similar sections are used for each of these particular zones, i.e. one for $z_{i} \leq \frac{N}{3}$, one for $\frac{N}{3}<z_{i} \leq \frac{2 N}{3}$, and one for $\frac{2 N}{3}<z_{i} \leq N$. Geometric nonlinear effects are controlled with the amplification of seismic loads according to Eurocode 8 Part 1, paragraph 4.4.2.2, equation 4.28. The link design resistances in bending and shear based on the previous design procedure, are computed according to Eurocode 8 Part 1 paragraph 6.8.2(3):

$$
\begin{gathered}
M_{p, \text { link }}=f_{y} b t_{f}\left(d-t_{f}\right) \\
V_{p, \text { link }}=\frac{f_{y}}{\sqrt{3}} t_{w}\left(d-t_{f}\right)
\end{gathered}
$$

where $f_{y}$ is the nominal yield stress; $d$ is the total depth of the section; $b$ is flange width; $t_{f}$ is flange thickness and $t_{w}$ is web thickness. The equation regarding the bending capacity of the links are however defined otherwise in Eurocode 3 [51] as,

$$
M_{p, \text { link }}=f_{y} Z_{\text {sec }}
$$

where $Z_{\text {sec }}$ is the effective section modulus. These equations were also used in the later derivation, mentioned in step 4 , to obtain an alternative relationship between the different section parameters and hence to compare the results with the EC8 equations for each type of structures. These sections are thus modified in step 4 to incorporate shear critical steel links (SCSL). Once the sections are defined, the link categories are determined according to Eurocode 8 Part 1 
paragraph 6.8.2(9) from their length $e$ according to the following scheme. Shorter links are preferred for this particular design procedure to emphasize upon the shear critical link behaviour. The link section and the link length are chosen by means of a trial-and-error iterative procedure.

Table 1. Link category criteria based on link length as recommended by Eurocode 8

\begin{tabular}{|c|c|c|}
\hline Short (Shear) Links & Intermediate Links & Long (Flexural) Links \\
\hline$e<e_{s}=0.8 \frac{M_{p, \text { link }}}{V_{p, \text { link }}}$ & $e_{s}<e<e_{L}$ & $e>e_{L}=1.5 \frac{M_{p, \text { link }}}{V_{p, \text { link }}}$ \\
\hline
\end{tabular}

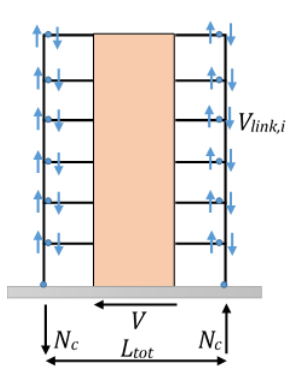

Fig. 2. Horizontal actions and relevant resisting forces (axial, and shear).

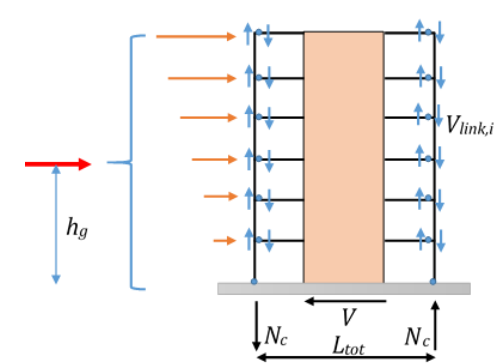

Fig. 3. Equilibrium of forces in the HCW system for the computation of the design base shear.

Step 4: Links can be designed as shear critical in three ways: using larger sections; decreasing link length; or increasing the flange thickness of the built-up I profile. As the first option proves to be rather uneconomical, a new relationship using both the later options was developed based upon W. S. Park and H. D. Yun's research work [52] to ensure greater energy dissipation by keeping the flanges of the coupling links elastic while the web yields in shear. Therefore, builtup I profiles (BuIP) were adopted for the steel links. The appropriate slenderness ratios were also taken into account to safely design the links against local flange or web buckling. While a link section is chosen based upon the moment and shear demands, the required section modulus, $\mathrm{Z}_{\text {req }}$, is determined and checked to ensure the steel coupling beam is shear critical. Therefore, the section should be chosen to develop a moment resistance, $\mathbf{M}_{\mathrm{s}}$, greater than or equal to the moment corresponding to the development of strain hardening in shear.

$$
Z_{\text {req }} \geq \frac{M_{s}}{\theta_{b} f_{y}} ; \quad M_{s}=1.35 V_{p, l i n k} l_{\text {link }}
$$

where $l_{\text {link }}$ is the link length (from the face of the column to the face of the RC wall therefore counting out eccentricities), $\theta_{\mathrm{b}}$ is the material reduction factor typically taken as 0.9 and the factor 1.35 accounts for the development of strain hardening in the web of the steel coupling link [52]. A factor of 1.2 instead of 1.35 is recommended by Eurocode 8 to account for the development of strain hardening. This factor is thus used to derive an alternative relation between the aforementioned parameters to compare the results with the present shear critical design procedure. In determining $\mathrm{Z}_{\mathrm{req}}$, the contribution of the web should be neglected, since it will yield in shear. Thus, to make the link shear critical, $\mathrm{M}_{\mathrm{p}, \mathrm{link}}$ should be equal to $\mathrm{M}_{\mathrm{s}}$ and following this concept a relationship can be derived as stated in Eq. 11 .

$$
\frac{b t_{f}}{t_{w}}=\frac{1.35 l_{\text {link }}}{\sqrt{3}}
$$




$$
e \leq l_{\text {link }}=0.74 \frac{M_{p, \text { link }}}{V_{p, \text { link }}}
$$

Link section and link length can be finalized as per this relationship. Also, following these derivations, a new factor of 0.74 was found (Eq. 12) and thus used to define a short link, which was $7.5 \%$ lesser than the factor of 0.8 recommended by Eurocode 8 as mentioned earlier. The following checks are required to ensure sufficient resistance of both the flange and web of the built up steel coupling link sections against local buckling.

$$
\frac{b}{t_{f}} \leq 0.31 \sqrt{\frac{E_{s}}{f_{y}}} ; \quad \frac{H}{t_{w}} \leq 3.05 \sqrt{\frac{E_{s}}{f_{y}}}
$$

where $b$ and $t_{f}$ are the width and thickness of the steel coupling link flange, $H$ and $t_{w}$ are the total height and thickness of the steel coupling link web, respectively.

Step 5: Design of the steel side columns using the summation of the yield shear forces of the links (amplified with $1.1 \gamma_{o v}$ ) as design axial force.

The steel side columns at the $i$-th floor are designed using the summation of the yield shear forces of the links:

$$
N_{c, E d}=1.1 \gamma_{o v} \sum_{i=1}^{n_{\text {links }}} V_{\text {link }, i}
$$

with $\gamma_{\mathrm{ov}}=1.25$. The effect of the eccentricity between the column axis and the shear connection between the link and the column should also be considered in the design.

Step 6: Design of the wall shear capacity.

The design of the wall transverse reinforcements as suggested [28] is made to provide a shear resistance $V_{R d, w}$ in the wall that exceeds the maximum shear $V_{p l, w}$ (estimated base shear):

$$
V_{R d, w}>V_{p l, w}=\frac{1}{H_{1}}\left[M_{w, R d}+1.1 \gamma_{o v}\left(l_{w}+2 l_{\text {link }}\right) \sum_{i=1}^{n_{\text {links }}} V_{\text {link }, i}\right]
$$

where $H_{l}$ is the resultant height of the fundamental mode inertial force distribution or a fundamental-mode based equivalent lateral force distribution. From the estimated maximum base shear at collapse, the transverse reinforcements for the reinforced concrete wall are designed.

\section{APPLICATION TO THE DUCTILE DESIGN OF THE INNO-HYCO HCW SYSTEM}

\subsection{Description of the Case Studies}

In order to check the aptness of the design modification, case studies with 3,6 and 12 storeys using different CRs are considered for a total of 30 designs ( 15 for the previous design procedure and 15 for the shear critical design procedure). Seismic design loads were calculated in accordance with Eurocode 8. The HCW system is assumed to be a part of a residential building for the seismic design considerations. The plan view as well as the front view, for a 6-storey building, is indicated in Fig. 4 with the adopted position of the HCW systems. The interstorey height is taken to be $3.50 \mathrm{~m}$, permanent floor loads $=4.30 \mathrm{kN} / \mathrm{m}^{2}$, variable floor loads $=2.00 \mathrm{kN} / \mathrm{m}^{2}$, permanent roof loads $=3.30 \mathrm{kN} / \mathrm{m}^{2}$, variable roof loads $=1.97 \mathrm{kN} / \mathrm{m}^{2}$. A previously recommended behaviour factor, $\mathrm{q}=3[27]$ is considered in the present 
designs. Indeed, further investigations are required to choose a more suitable behaviour factor as use of shear critical links might encourage a different and possibly higher value. Concrete for the RC wall in all cases, is class $\mathrm{C} 30$ (characteristic cylindrical compressive strength $\mathrm{f}_{\mathrm{ck}}=30 \mathrm{MPa}$ ) and reinforcements are $\mathrm{B} 450 \mathrm{C}$ (characteristic yield stress $\mathrm{f}_{\mathrm{yk}}=450 \mathrm{MPa}$ ) as per Eurocode 2 [53]. Reinforcements are designed according to the DCM rules stated in Eurocode 8, Clause 5.4.3.4 for ductile walls. Steel links are designed as Built-up I Profiles (BuIP) for different CRs along with uniform and non-uniform distributions (when the CR value is greater than the critical limit) in order to investigate the altering behaviour of the RC wall. Steel grade S355 (nominal yield stress, $\mathrm{f}_{\mathrm{y}}=355 \mathrm{Mpa}$ ) is adopted for both the coupling links and the steel side columns. The links lengths are chosen through a path of trial and error, depending upon their mechanical properties and their compatibility towards being short links. After the steel links are finalized, the steel side columns are designed for the amplified axial force demand as per Eq. 14. Column sections are chosen from European HE profiles classified as Class 1 or 2 sections in compression (i.e. compact sections) according to Eurocode 3 [51]. The same column section chosen for a specific CR is used for all the storeys to avoid variations in link lengths and avoid detailing and construction complications. Lastly, the shear design of the RC wall is carried out for the base shear estimated from Eq. 15 , where $\mathrm{H}_{1}=2 / 3 \mathrm{H}$ represents a triangular distribution and $\mathrm{H}_{1}=1 / 2 \mathrm{H}$ represents a uniform distribution of horizontal forces.

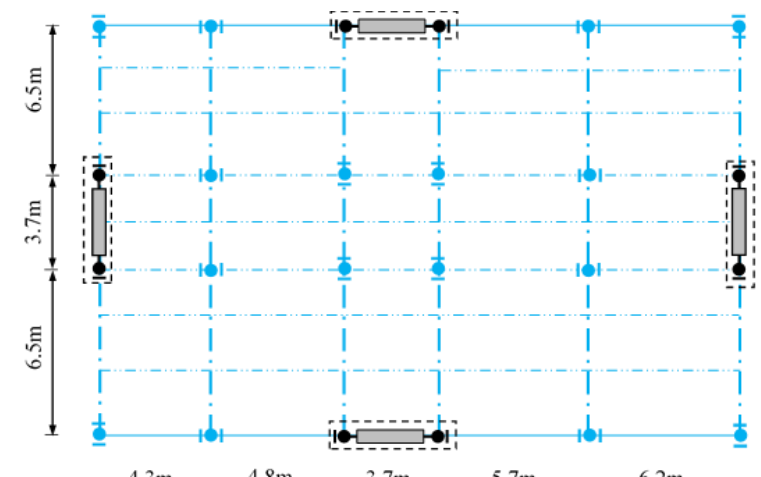

(a) (b)

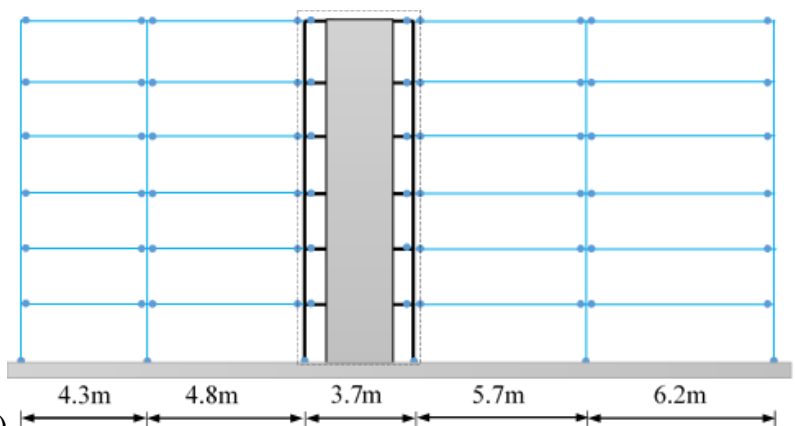

Fig. 4. (a) Plan view and (b) Floor geometry with positions of the HCW systems for a 6-storey structure

\subsubsection{Case Study 1: 3-Storey Structure}

According to the total height of the building $(H)=10.5 \mathrm{~m}$ and the suggested ratio, $\mathrm{H} / \mathrm{l}_{\mathrm{w}}=10$ [27, 49], the dimensions of the RC wall section is calculated to be $1.05 \mathrm{~m}$ in length $\left(1_{\mathrm{w}}\right)$. The width is primarily assumed to be $0.5 \mathrm{~m}$. The designed wall section is illustrated in Fig. 5. Table 2 shows the outcomes of link and column design. The base shears estimated using both values of $\mathrm{H}_{1}$ according to the modified design procedure using shear critical steel links are shown in Table 3 and the base shears using both values of $\mathrm{H}_{1}$ according to the previous design procedure [28] using regular steel links are shown in Table 4. 


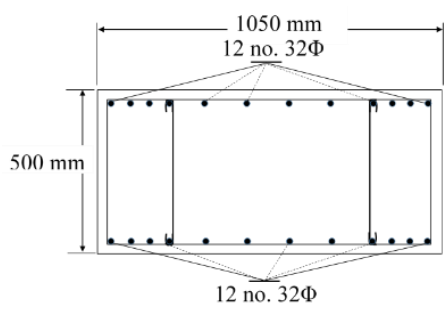

Fig. 5. Detailing of the reinforcements designed for the RC wall of the 3-storey structure

Table 2. Designed Links with their properties and Side Columns for the 3-storey structure

\begin{tabular}{lllll|lll}
\hline CR & $\mathbf{0 . 4}$ & $\mathbf{0 . 5}$ & $\mathbf{0 . 6}$ & $\mathbf{0 . 7}$ & \multicolumn{3}{c}{ 0.7 Non-uniform } \\
\hline Link Section & BuIP_1 & BuIP_2 & BuIP_3 & BuIP_4 & BuIP_5 & BuIP_6 & BuIP_7 \\
Link Length $(\mathrm{mm})$ & 300 & 400 & 550 & 600 & 600 & 600 & 600 \\
Section Depth, H (m) & 0.240 & 0.300 & 0.360 & 0.450 & 0.270 & 0.450 & 0.550 \\
Flange Width, b (m) & 0.100 & 0.120 & 0.140 & 0.140 & 0.120 & 0.160 & 0.180 \\
Flange Thickness, $\mathrm{t}_{\mathrm{f}}(\mathrm{m})$ & 0.0144 & 0.0184 & 0.0244 & 0.031 & 0.026 & 0.028 & 0.029 \\
Web Thickness, $\mathrm{t}_{\mathrm{w}}(\mathrm{m})$ & 0.0062 & 0.0071 & 0.0080 & 0.0086 & 0.0066 & 0.0094 & 0.0111 \\
Section Modulus, $\mathrm{Z}$ & 0.00035 & 0.00065 & 0.00118 & 0.00188 & 0.00073 & 0.00198 & 0.00297 \\
Flange buckling check, b/t $\mathrm{f}$ & 6.89 & 6.50 & 5.71 & 4.46 & 4.66 & 5.82 & 6.24 \\
Web buckling check, H/t $\mathrm{w}_{\mathrm{w}}$ & 38.70 & 42.20 & 45.00 & 47.80 & 42.25 & 47.8 & 49.5 \\
\hline $\mathrm{e}_{\mathrm{l}}(\mathrm{m})$ & 0.607 & 0.810 & 1.113 & 1.215 & 1.215 & 1.215 & 1.215 \\
$\mathrm{e}_{\mathrm{s}}(\mathrm{m})$ & 0.324 & 0.432 & 0.594 & 0.648 & 0.648 & 0.648 & 0.648 \\
Link Classification & & & & Short & & & 1 \\
Storey & All & All & All & All & 3 & 2 & 1.67 \\
Distribution Coefficient & 1.00 & 1.00 & 1.00 & 1.00 & 0.33 & 1.00 & 1152.26 \\
Shear Demand $(\mathrm{kN})$ & 269.36 & 360.36 & 465.12 & 691.36 & 230.45 & 691.36 \\
Moment Demand $(\mathrm{kNm})$ & 80.80 & 144.14 & 255.80 & 414.80 & 138.27 & 414.80 & 691.36 \\
Yield Shear, $\mathrm{V}_{\mathrm{p}}(\mathrm{kN})$ & 286.68 & 409.79 & 550.29 & 738.57 & 330.07 & 813.05 & 1185.33 \\
Yield Moment, $\mathrm{M}_{\mathrm{p}}(\mathrm{kNm})$ & 115.32 & 220.73 & 406.97 & 645.55 & 270.25 & 671.15 & 965.46 \\
\hline Columns & HE 300B & HE 300B & HE $400 \mathrm{~B}$ & HE 500B & & HE 500B \\
\hline
\end{tabular}

Table 3. Total base shear estimated from the modified design procedure (Shear critical) of the 3 -storey structure

\begin{tabular}{llllll}
\hline \multicolumn{1}{c}{} & $\mathbf{0 . 4}$ & $\mathbf{0 . 5}$ & $\mathbf{0 . 6}$ & $\mathbf{0 . 7}$ & $\begin{array}{l}\text { 0.7 } \\
\text { Non-uniform }\end{array}$ \\
\hline $\begin{array}{l}\text { Estimated base Shear for } \\
\mathrm{H}_{1}=1 / 2 \mathrm{H}(\mathrm{kN})\end{array}$ & 943.1 & 1167.1 & 1501.0 & 1877.1 & 1943.5 \\
$\begin{array}{l}\text { Estimated base Shear for } \\
\mathrm{H}_{1}=2 / 3 \mathrm{H}(\mathrm{kN})\end{array}$ & 707.3 & 875.3 & 1125.7 & 1407.8 & 1457.7 \\
\hline
\end{tabular}


Table 4. Total base shear estimated from the Zona et al, 2016 design procedure [28] of 3-storey structure

\begin{tabular}{llllll}
\hline \multicolumn{1}{c}{} & $\mathbf{0 . 4}$ & $\mathbf{0 . 5}$ & $\mathbf{0 . 6}$ & $\mathbf{0 . 7}$ & \multicolumn{1}{c}{ No.7 } \\
\hline $\begin{array}{l}\text { Estimated base Shear for } \\
\mathrm{H}_{1}=1 / 2 \mathrm{H}(\mathrm{kN})\end{array}$ & 950.7 & 1183.4 & 1533.4 & 2054.4 & 2155.9 \\
$\begin{array}{l}\text { Estimated base Shear for } \\
\mathrm{H}_{1}=2 / 3 \mathrm{H}(\mathrm{kN})\end{array}$ & 713.0 & 887.5 & 1150.1 & 1540.8 & 1616.9 \\
\hline
\end{tabular}

\subsubsection{Case Study 2: 6-Storey Structure}

In relation to the total height of the building $(\mathrm{H})=21 \mathrm{~m}$ and the suggested ratio, $\mathrm{H} / \mathrm{l}_{\mathrm{w}}=10$, the length of the $\mathrm{RC}$ wall section is calculated to be $2.1 \mathrm{~m}\left(\mathrm{l}_{\mathrm{w}}\right)$. The width is primarily assumed to be $0.36 \mathrm{~m}$ as shown in Fig. 6 . Table 5 shows the outcomes of link and column design, whereas, Table 6 and 7 lists the base shears estimated using shear critical and previously designed steel links [28] respectively.

Table 5. Designed Links with their properties and Side Columns for 6-storey structure

\begin{tabular}{|c|c|c|c|c|c|c|}
\hline $\mathbf{C R}$ & 0.4 & 0.6 & 0.8 & \multicolumn{3}{|c|}{ 0.8 Non-uniform } \\
\hline Link Section & BuIP_8 & BuIP_9 & BuIP_10 & BuIP_9 & BuIP_10 & BuIP_11 \\
\hline Link Length (mm) & 400 & 500 & 500 & 500 & 500 & 500 \\
\hline Section Depth, H (m) & 0.200 & 0.220 & 0.400 & 0.220 & 0.400 & 0.500 \\
\hline Flange Width, b (m) & 0.100 & 0.110 & 0.140 & 0.110 & 0.140 & 0.150 \\
\hline Flange Thickness, $\mathrm{t}_{\mathrm{f}}(\mathrm{m})$ & 0.017 & 0.020 & 0.024 & 0.020 & 0.024 & 0.026 \\
\hline Web Thickness, $\mathrm{t}_{\mathrm{w}}(\mathrm{m})$ & 0.0056 & 0.0059 & 0.0086 & 0.0059 & 0.0086 & 0.0102 \\
\hline Section Modulus, Z & 0.0003 & 0.0004 & 0.0013 & 0.0004 & 0.0013 & 0.0021 \\
\hline Flange buckling check, $\mathrm{b} / \mathrm{t}_{\mathrm{f}}$ & 5.73 & 5.26 & 5.84 & 5.26 & 5.84 & 5.66 \\
\hline Web buckling check, $\mathrm{H} / \mathrm{t}_{\mathrm{w}}$ & 36.00 & 37.29 & 46.50 & 37.29 & 46.50 & 49.01 \\
\hline $\mathrm{e}_{\mathrm{l}}(\mathrm{m})$ & 0.8100 & 1.0125 & 1.0125 & 1.0125 & 1.0125 & 1.0125 \\
\hline $\mathrm{e}_{\mathrm{s}}(\mathrm{m})$ & 0.4320 & 0.5400 & 0.5400 & 0.5400 & 0.540 & 0.5400 \\
\hline Link Classification & \multicolumn{6}{|c|}{ Short } \\
\hline Storey & All & All & All & 6,5 & 4,3 & 2,1 \\
\hline Distribution Coefficient & 1.00 & 1.00 & 1.00 & 0.33 & 1.00 & 1.67 \\
\hline Shear Demand $(\mathrm{kN})$ & 103.44 & 217.74 & 580.64 & 193.54 & 580.64 & 967.74 \\
\hline Moment Demand (kNm) & 41.37 & 108.87 & 290.32 & 96.77 & 290.32 & 483.87 \\
\hline Yield Shear, $\mathrm{V}_{\mathrm{p}}(\mathrm{kN})$ & 210.05 & 241.86 & 662.70 & 241.86 & 662.77 & 990.96 \\
\hline Yield Moment, $\mathrm{M}_{\mathrm{p}}(\mathrm{kNm})$ & 110.44 & 156.20 & 448.49 & 156.2 & 448.49 & 656.25 \\
\hline Columns & HE 300B & HE 400B & HE 700M & \multicolumn{3}{|c|}{ HE 700M } \\
\hline
\end{tabular}




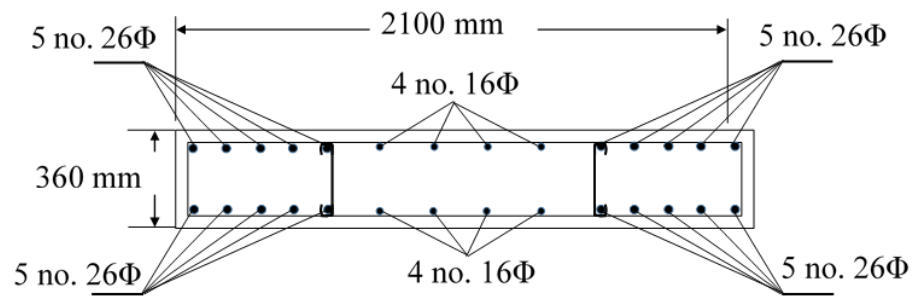

Fig. 6. Detailing of the reinforcements designed for the RC wall of the 6-storey structure

Table 6. Total base shear estimated from the modified design procedure (Shear critical) of the 6-storey structure

\begin{tabular}{llccc}
\hline CR & $\mathbf{0 . 4}$ & $\mathbf{0 . 6}$ & $\mathbf{0 . 8}$ & 0.8 Non-uniform \\
\hline Estimated base Shear for $\mathrm{H}_{1}$ & 864.3 & 974.8 & 2000.0 & 1924.7 \\
$=1 / 2 \mathrm{H}(\mathrm{kN})$ & & & & \\
Estimated base Shear for $\mathrm{H}_{1}$ & 648.2 & 731.1 & 1500.0 & 1443.6 \\
$=2 / 3 \mathrm{H}(\mathrm{kN})$ & & & & \\
\hline
\end{tabular}

Table 7. Total base shear estimated from the Zona et al, 2016 design procedure [28] of the 6-storey structure

\begin{tabular}{lllll}
\hline $\mathbf{C R}$ & $\mathbf{0 . 4}$ & $\mathbf{0 . 6}$ & $\mathbf{0 . 8}$ & $\mathbf{0 . 8}$ Non-uniform \\
\hline Estimated base Shear for $\mathrm{H}_{1}$ & 966.6 & 1241.7 & 2054.5 & 2054.5 \\
$=1 / 2 \mathrm{H}(\mathrm{kN})$ & & & \\
Estimated base Shear for $\mathrm{H}_{1}$ & 724.9 & 931.3 & 1540.8 & 1540.8 \\
$=2 / 3 \mathrm{H}(\mathrm{kN})$ & & & & \\
\hline
\end{tabular}

\subsubsection{Case Study 3: 12-Storey Structure}

In relation to the total height of the building $(\mathrm{H})=42$ and the suggested ratio, $\mathrm{H} / \mathrm{I}_{\mathrm{w}}=10$, the dimensions of the $\mathrm{RC}$ wall section is calculated to be $4.2 \mathrm{~m}$ in length $\left(1_{\mathrm{w}}\right)$. The width is primarily assumed to be $0.36 \mathrm{~m}$ as shown in Fig. 7 . Table 8 and Table 9 show the outcomes of link and column design for the uniform and non-uniform shear distribution case respectively. The base shears of the $\mathrm{RC}$ wall estimated using both values of $\mathrm{H}_{1}$ for both the modified shear design and the previous design [28] are shown in Table 10 and Table 11.

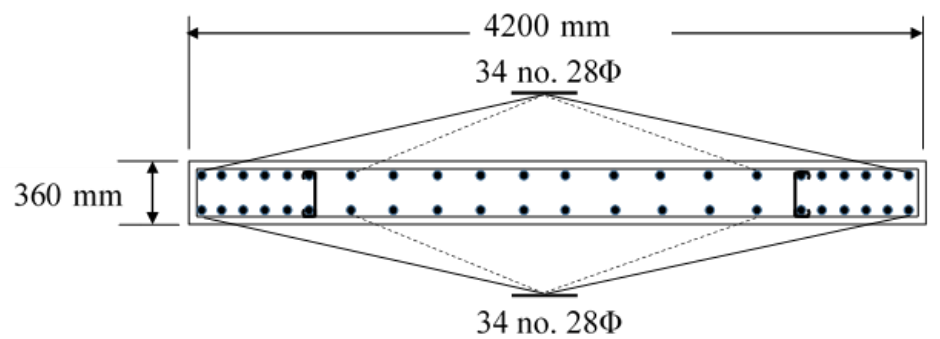

Fig. 7. Detailing of the reinforcements designed for the RC wall of the 12-storey structure 
Table 8. Designed Links with their properties and Side Columns for the 12-storey structure (Uniform Link Distribution case)

\begin{tabular}{lllll}
\hline CR & $\mathbf{0 . 4}$ & $\mathbf{0 . 5}$ & $\mathbf{0 . 6}$ & $\mathbf{0 . 7}$ \\
\hline Link Section & BuIP_12 & BuIP_13 & BuIP_14 & BuIP_15 \\
Link Length $(\mathrm{mm})$ & 400 & 400 & 500 & 500 \\
Section Depth, $\mathrm{H}(\mathrm{m})$ & 0.220 & 0.270 & 0.330 & 0.450 \\
Flange Width, $\mathrm{b}(\mathrm{m})$ & 0.110 & 0.120 & 0.125 & 0.140 \\
Flange Thickness, $\mathrm{t}_{\mathrm{f}}(\mathrm{m})$ & 0.0167 & 0.0179 & 0.0233 & 0.0260 \\
Web Thickness, $\mathrm{t}_{\mathrm{w}}(\mathrm{m})$ & 0.0059 & 0.0066 & 0.0075 & 0.0094 \\
Section Modulus, $\mathrm{Z}$ & 0.00037 & 0.00056 & 0.00092 & 0.00167 \\
\hline Flange buckling check, b/t & 6.57 & 6.99 & 5.34 & 5.35 \\
Web buckling check, H/t $\mathrm{t}_{\mathrm{w}}$ & 37.28 & 40.90 & 44.00 & 47.87 \\
\hline $\mathrm{e}_{\mathrm{l}}(\mathrm{m})$ & 0.8100 & 0.8100 & 1.0125 & 1.0125 \\
$\mathrm{e}_{\mathrm{s}}(\mathrm{m})$ & 0.4320 & 0.4320 & 0.5400 & 0.5400 \\
Link Classification & & & Short & \\
Storey & All & All & All & All \\
Distribution Coefficient & 1.00 & 1.00 & 1.00 & 1.00 \\
Shear Demand $(\mathrm{kN})$ & 207.40 & 311.11 & 432.69 & 673.08 \\
Moment Demand $(\mathrm{kNm})$ & 82.96 & 124.44 & 216.34 & 336.54 \\
Yield Shear, $\mathrm{V}_{\mathrm{p}}(\mathrm{kN})$ & 245.85 & 341.03 & 471.47 & 816.91 \\
Yield Moment, $\mathrm{M}_{\mathrm{p}}(\mathrm{kNm})$ & 132.58 & 192.24 & 317.11 & 547.89 \\
\hline Columns & HE $400 \mathrm{~B}$ & HE $700 \mathrm{M}$ & HE $700 \mathrm{M}$ & HE 700M \\
\hline
\end{tabular}

Table 9. Designed Links with their properties and Side Columns for the 12-storey structure (non-uniform Link Distribution case)

\begin{tabular}{lllllll}
\hline CR & \multicolumn{3}{c}{ 0.6 Non-uniform } & \multicolumn{3}{c}{ 0.7 Non-uniform } \\
\hline Link Section & BuIP_9 & BuIP_14 & BuIP_15 & BuIP_9 & BuIP_15 & BuIP_16 \\
Link Length (mm) & 500 & 500 & 500 & 500 & 500 & 500 \\
Section Depth, H (m) & 0.220 & 0.330 & 0.450 & 0.220 & 0.450 & 0.550 \\
Flange Width, b (m) & 0.110 & 0.125 & 0.140 & 0.110 & 0.140 & 0.170 \\
Flange Thickness, $\mathrm{t}_{\mathrm{f}}(\mathrm{m})$ & 0.0200 & 0.0233 & 0.0260 & 0.0200 & 0.0260 & 0.0254 \\
Web Thickness, $\mathrm{t}_{\mathrm{w}}(\mathrm{m})$ & 0.0059 & 0.0075 & 0.0094 & 0.0059 & 0.0094 & 0.0111 \\
Section Modulus, Z & 0.00043 & 0.00092 & 0.00167 & 0.00043 & 0.00167 & 0.00258 \\
Flange buckling check, b/t $\mathrm{t}_{\mathrm{f}}$ & 5.26 & 5.34 & 5.35 & 5.26 & 5.35 & 6.68 \\
Web buckling check, H/t $\mathrm{t}_{\mathrm{w}}$ & 37.29 & 44.00 & 47.87 & 37.29 & 47.87 & 49.50 \\
\hline $\mathrm{e}_{\mathrm{l}}(\mathrm{m})$ & 1.0125 & 1.0125 & 1.0125 & 1.0125 & 1.0125 & 1.0125 \\
$\mathrm{e}_{\mathrm{s}}(\mathrm{m})$ & 0.5400 & 0.5400 & 0.5400 & 0.5400 & 0.5400 & 0.5400
\end{tabular}


Link Classification

Storey

Distribution Coefficient

Shear Demand $(\mathrm{kN})$

Moment Demand (kNm)

Yield Shear, $\mathrm{V}_{\mathrm{p}}(\mathrm{kN})$

Yield Moment, $\mathrm{M}_{\mathrm{p}}(\mathrm{kNm})$
$12,11,10,9$

0.33

144.23

72.11

241.86

156.20

Short

$\begin{array}{lll}\text { Columns } & \text { HE 700M } & \text { HE 700M }\end{array}$

Table 10. Total base shear estimated from the modified design procedure (Shear critical) of the 12-storey structure

\begin{tabular}{lllllll}
\hline CR & $\mathbf{0 . 4}$ & $\mathbf{0 . 5}$ & $\mathbf{0 . 6}$ & $\mathbf{0 . 6}$ Non-uniform & $\mathbf{0 . 7}$ & 0.7 Non-uniform \\
\hline $\begin{array}{l}\text { Estimated base Shear } \\
\text { for } \mathrm{H}_{1}=1 / 2 \mathrm{H}(\mathrm{kN})\end{array}$ & 2299.2 & 2673.1 & 3259.6 & 3417.3 & 4670.9 & 4400.7 \\
$\begin{array}{l}\text { Estimated base Shear } \\
\text { for } \mathrm{H}_{1}=2 / 3 \mathrm{H}(\mathrm{kN})\end{array}$ & 1724.4 & 2004.8 & 2444.7 & 2563.0 & 3503.2 & 3300.5 \\
\hline
\end{tabular}

Table 11. Total base shear estimated from the Zona et al, 2016 design procedure [28] of the 12-storey structure

\begin{tabular}{lllllll}
\hline CR & $\mathbf{0 . 4}$ & $\mathbf{0 . 5}$ & $\mathbf{0 . 6}$ & $\mathbf{0 . 6}$ Non-uniform & $\mathbf{0 . 7}$ & 0.7 Non-uniform \\
\hline $\begin{array}{l}\text { Estimated base Shear } \\
\text { for } \mathrm{H}_{1}=1 / 2 \mathrm{H}(\mathrm{kN})\end{array}$ & 2482.6 & 2714.0 & 3612.4 & 3550.9 & 4713.1 & 4557.7 \\
$\begin{array}{l}\text { Estimated base Shear } \\
\text { for } \mathrm{H}_{1}=2 / 3 \mathrm{H}(\mathrm{kN})\end{array}$ & 1861.9 & 2035.5 & 2709.3 & 2663.2 & 3534.8 & 3418.3 \\
\hline
\end{tabular}

\section{FINITE ELEMENT MODEL OF THE INNO-HYCO HCW SYSTEMS}

The HCW systems are modelled and analysed through nonlinear static and dynamic analyses by means of a plane model implemented in the finite element software SAP 2000 [54]. The RC wall, steel shear links as well as the steel side columns are modelled using linear elastic frame elements (axial, flexural and shear deformability) while the nonlinear behaviour is included using flexural/shear hinges. Specifically, plastic flexural hinges are introduced at both ends of each tract between two subsequent floors of the RC wall. The plastic hinge properties are calculated manually, based on the nonlinear analysis of the individual wall sections as prescribed by the Eurocode 2 and provided as input information in the required SAP window. As already illustrated, the shear capacity of the wall is designed by enforcing over-strength through considering the maximum shear at the base derived from the limit condition of yielded steel links and yielded wall in bending. In addition, reinforcements are detailed according to the Eurocode 8 DCM rules. These design conditions result in ductile walls dominated by the flexural behaviour. Accordingly, plastic flexural hinges only are introduced while the nonlinear behaviour in shear of the RC wall is not included in the model. 
The steel coupling links are assumed to be pinned to the face of the steel side columns and are fixed to the face of the RC wall. Eccentricities of the connections are incorporated through rigid links in SAP 2000. Plastic shear hinges are introduced at the midpoint of the links as shear force stays constant throughout the link length. As maximum bending moment occurs at the link end fixed to the shear wall, plastic flexural hinges are introduced at those connection points only to verify that the sections yield in shear prior to flexure.

The base of the steel side columns are pinned to the ground, whereas the base of the RC wall is fixed. Nonlinear direct integration time histories with isotropic hysteresis behaviour of the plastic hinges is adopted for the nonlinear dynamic analyses. Fig. 8 shows a schematic view of the adopted models.

(a)

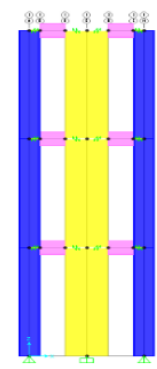

(b)

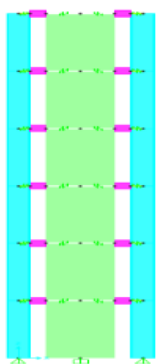

(c)

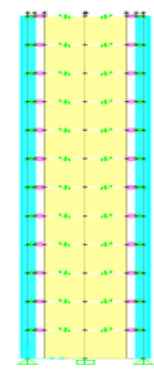

Fig. 8. SAP 2000 models: (a) 3-storey structure; (b) 6-storey structure; and (c) 12-storey structure

\section{STUDY OF THE SEISMIC BEHAVIOUR BASED ON PUSHOVER ANALYSIS}

\subsection{Critical limit and ultimate limit of CR}

Nonlinear pushover analyses are carried over considering two types of distributions: lateral loads proportional to the first modal deformation and lateral loads proportional to the mass. Results obtained in both these cases resemble from a qualitative point of view such as, yielding pattern in the links and RC wall, while the major difference being the larger base shear and slightly lower displacement obtained in the latter case, as already observed in [28]. Therefore, results are shown for the case of loads proportional to the first modal deformation.

The curves illustrating the base shear versus the horizontal displacement of the top most point of the HCW system for the uniform link distribution of the 3-storey-storey structure are shown in Fig. 9 for CRs 40\%, 50\%, 60\%, and $70 \%$. Each curve represents four critical events: (a) first yielding in the steel links; (b) all links yielded; (c) first yielding in the steel reinforcements in the RC wall (attained at the base of the RC wall); and (d) collapse, i.e. ultimate deformation in the $\mathrm{RC}$ wall while steel links have not yet reached their ultimate deformation for all considered case studies. The final two critical events related to the RC wall, are obtained from a plastic hinge model considering the plastic rotation capacities of the wall. It is observed that the design objective is satisfied as the first yielding in one of the links always occur prior to any yielding in the reinforcements of the RC wall. However, the attainment of the condition of all links yielded varies significantly with the CRs, as already observed in [28], with the higher CRs having damage in RC walls before all links start to dissipate seismic energy through plastic deformation. Thus, a non-uniform distribution of steel links is required for the higher values of CR [28]. The non-uniform link distribution provides an effective solution as shown in the pushover curves in Fig. 10. The design objectives can be fulfilled for a CR equal or below a specific value with the uniform link distribution. This can be called as the critical limit of CR. Thus, the critical 
limit of CR for uniform link distribution of a 3-storey building is $60 \%$. Pushover curves for the uniform link distribution of the 6-storey structure are shown in Fig. 11 for CRs 40\%, 60\%, and 80\% and curves illustrating the comparison between the uniform and non-uniform link distributions for CR $80 \%$ are shown in Fig. 12. The critical limit of CR for the 6-storey structure is also found to be $60 \%$. However, it is determined to be $50 \%$ for the 12 -storey structure as shown in Figs. 13 and 14 respectively.

Even after designing the structures with the assumed non-uniform distribution of links, the ductility targets (the RC wall remains in the elastic range while the steel links undergo ultimate shear deformations) are not fulfilled for a CR value greater than $80 \%$ for the 3 and 6 storey buildings, and similarly above $70 \%$ for 12 -storey buildings. This highest limit of CR is here called as the ultimate limit of CR. The minimum values of CR for an efficient ductile design were found out to be $40 \%$ for the 3- and 6-storey while it was 30\% for the 12-storey structures.

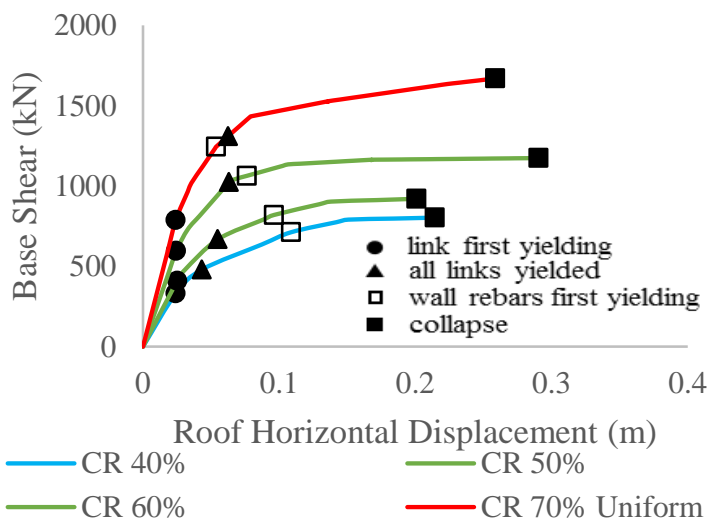

Fig. 9. Pushover curves for CR from $40 \%$ to $70 \%$ using Uniform link distribution for 3-storey structure

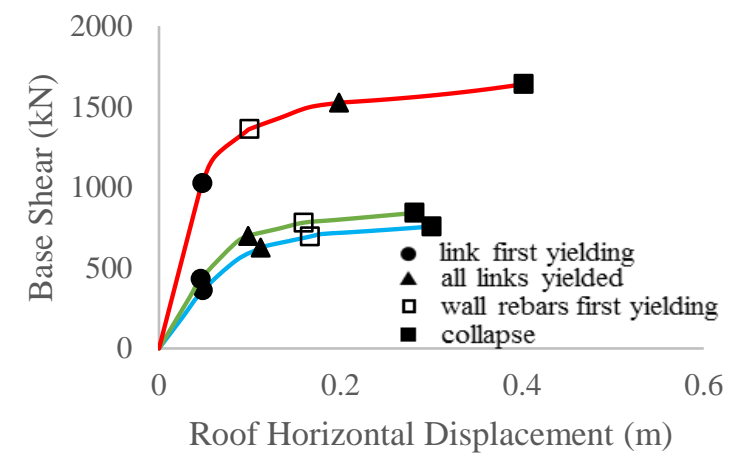

Fig. 11. Pushover curves for CR from $40 \%$ to $80 \%$ using Uniform link distribution for 6-storey structure

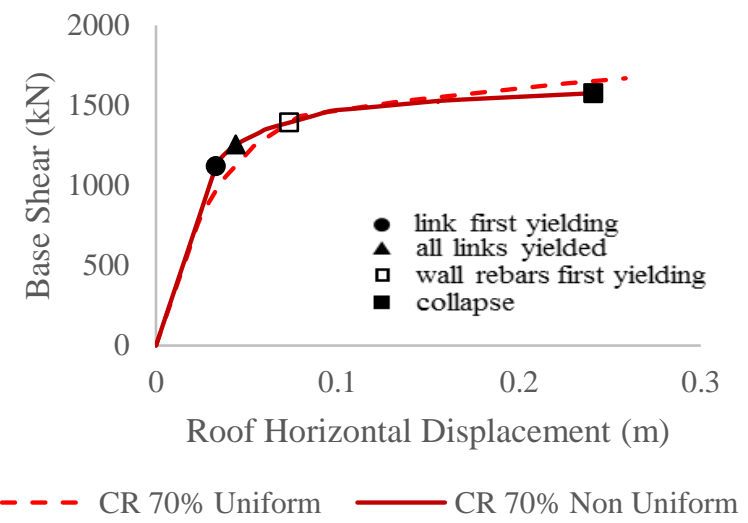

Fig. 10. Pushover curves for CR $70 \%$ using NonUniform and Uniform link distribution for 3-storey structure

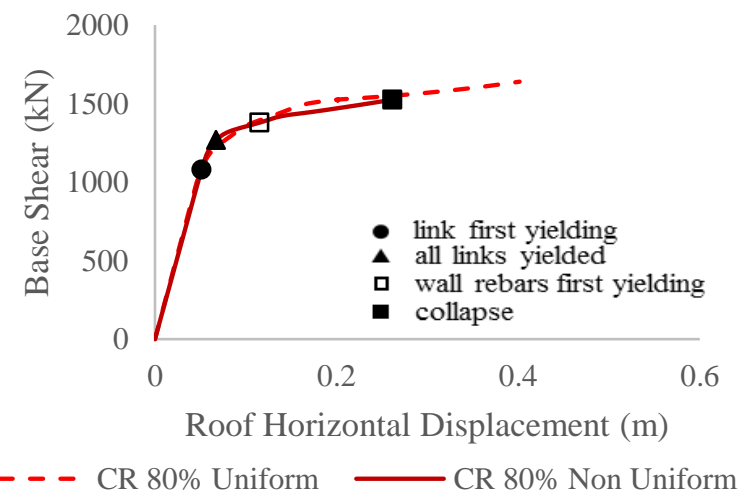

Fig. 12. Pushover curves for CR $80 \%$ using NonUniform and Uniform link distribution for 6-storey structure 


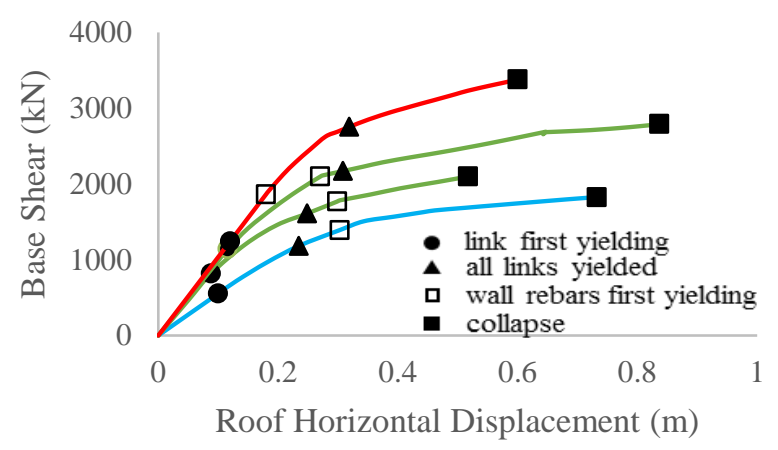

$-\mathrm{CR} 40 \%-\mathrm{CR} 50 \%-\mathrm{CR} 60 \%-\mathrm{CR} 70 \%$

Fig. 13. Pushover curves for CR from $40 \%$ to $70 \%$ using Uniform link distribution for 12-storey structure

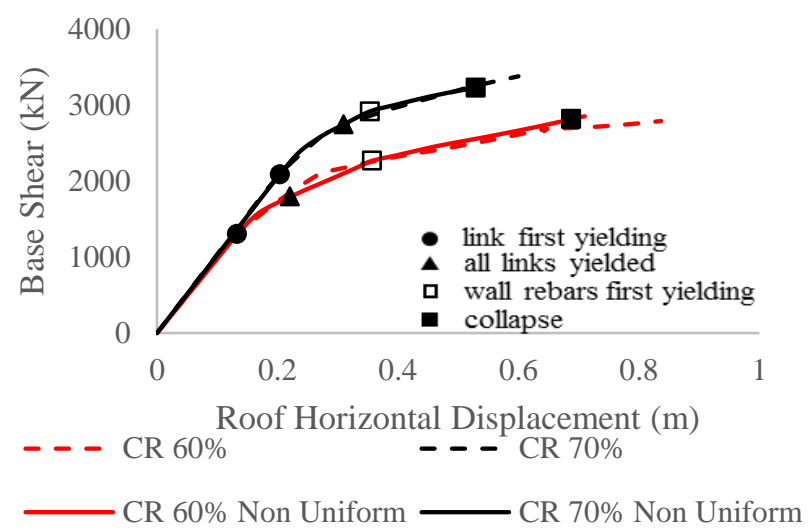

Fig. 14. Pushover curves for CR $60 \%$ and $70 \%$ using Non-Uniform and Uniform link distribution for -storey structure

\subsection{Comparisons of shear design approaches}

The pushover analysis is adopted in this paragraph to compare four different design approaches: (a) the approach presented in [28] and referred here as ZDLD design approach; (b) shear critical design presented in this work with a strain hardening (SH) factor of 1.35; (c) approach considering an unit SH factor; and (d) shear critical design with a SH factor 1.2. The pushover curves reporting the base shear versus roof horizontal displacement for the 6-storey structure are shown in Fig. 15, 16, 17 and 18 for CRs varying from $40 \%$ to $80 \%$ with uniform and non-uniform distribution of the dissipative steel links respectively. In each curve four events are marked: first yielding in the steel links; all links yielded; first yielding in the steel reinforcements in the RC wall (in all cases at the base of the RC wall); and collapse (in all case at the bottom of the RC wall). From the comparison between these different pushover results for a particular structure, it is observed that structures designed with shear links with SH factor 1.35 (b) attract lesser base shear for a particular displacement value and allows for an overall higher displacement than the structures designed by the ZDLD approach (a). An eminent inference can also be drawn regarding the conservative nature of the approach considering an unit SH factor (c), whereas the shear critical design with SH factor of 1.2 does not give rise to any noteworthy variations (d) when compared with shear design with SH factor 1.35 (b).

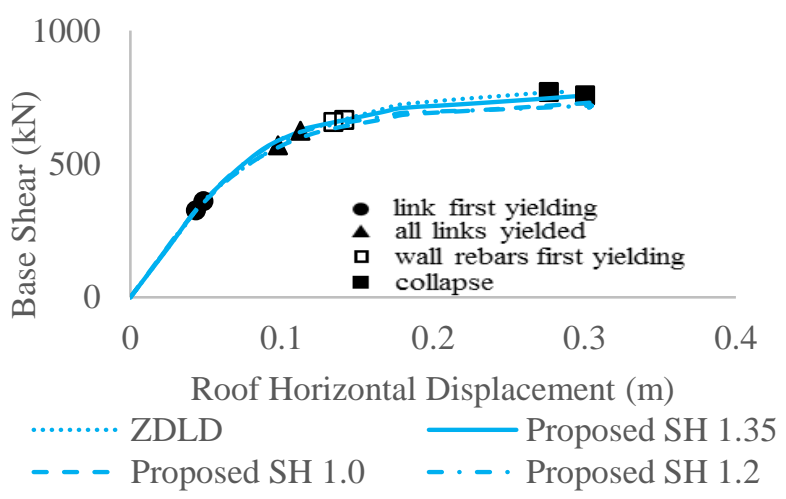

Fig. 15. Pushover curve comparisons for CR $40 \%$ using Uniform link distribution for 6-storey structure

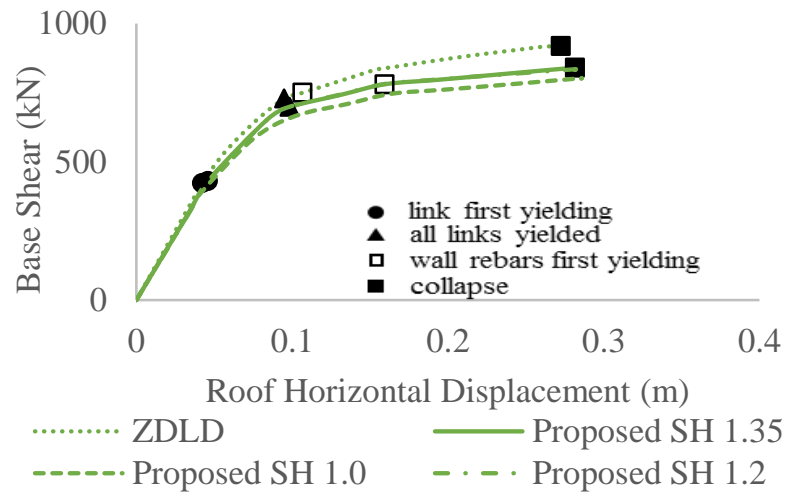

Fig. 16. Pushover curve comparisons for CR $60 \%$ using Uniform link distribution for 6-storey structure 


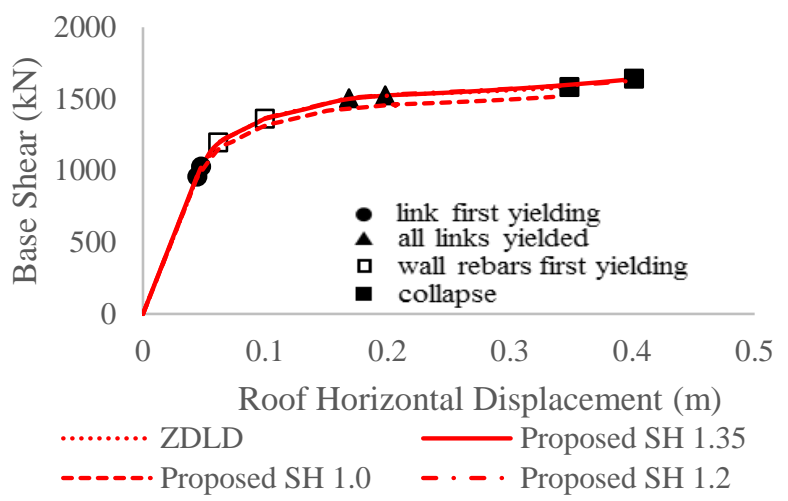

Fig. 17. Pushover curve comparisons for CR $80 \%$ using Uniform link distribution for 6-storey structure

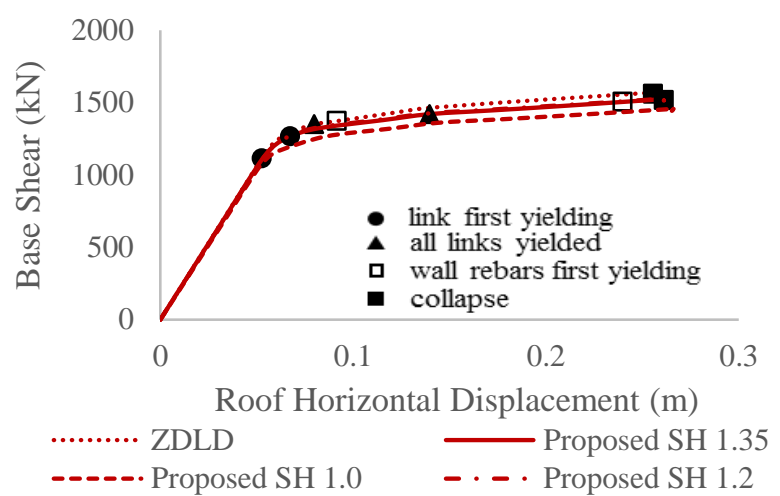

Fig. 18. Pushover curve comparisons for CR $80 \%$ using Non-Uniform link distribution for 6-storey structure

Pushover analyses of a 3- and a 12-storey HCW system are also conducted in order to verify the proposed design modifications. Fig. 19 and Fig. 20 illustrates the comparisons between the pushover curves for a 3 and a 12-storey HCW system respectively. From Fig. 19 and Fig. 20, an expected reduction in the base shear and greater allowance to the total displacement characteristics are observed for the structures designed with shear critical links. However, as the CR increases for the 6- and 12-storey structure, the difference between the two design procedures are phased out and therefore no significant alteration in the pushover curves are observed for the CRs above their critical limit. The reason behind this is the selection of larger hot-rolled IPE sections for the links following the ZDLD design approach [28].

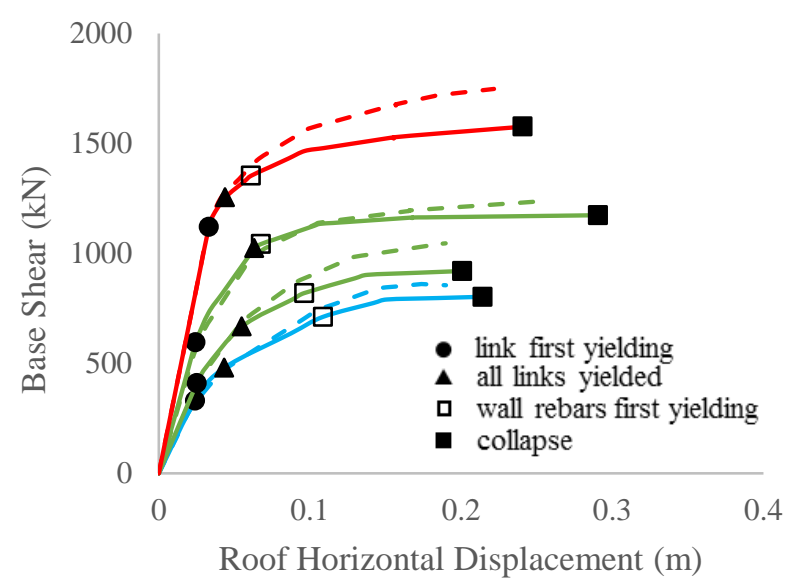

$$
\begin{array}{ll}
--- \text { ZDLD CR 40\% } & --- \text { ZDLD CR 50\% } \\
--- \text { ZDLD CR 60\% } & --- \text { ZDLD CR 70\% NU } \\
- \text { Shear CR 40\% } & \text { Shear CR 50\% } \\
\hline \text { Shear CR 60\% } & \text { Shear CR 70\% NU }
\end{array}
$$

Fig. 19. Pushover curve comparisons for CR from $40 \%$ to $70 \%$ using Uniform and Non-Uniform (NU) link distribution for 3-storey structure
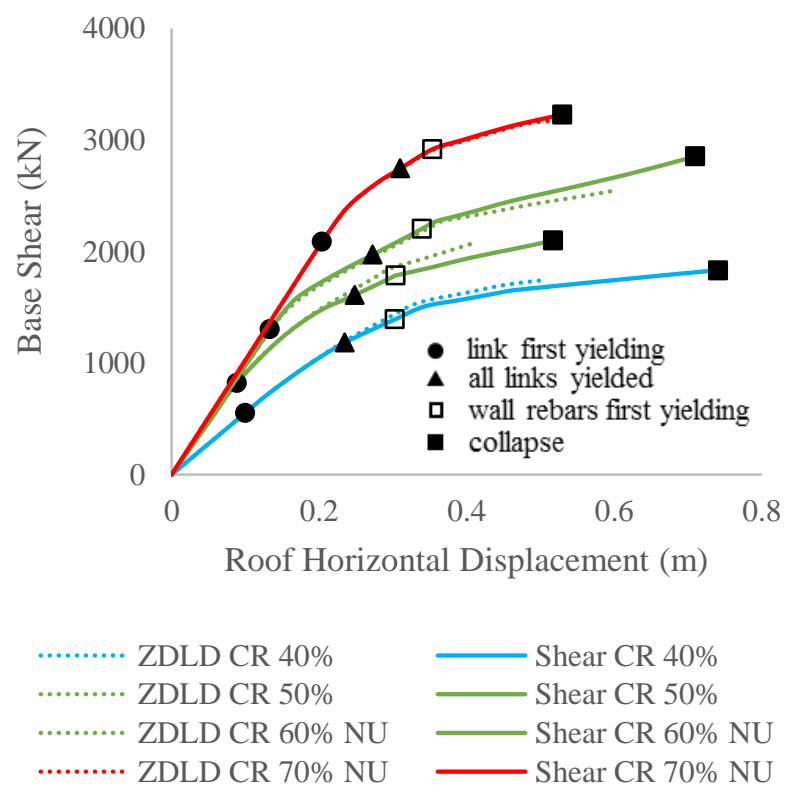

Fig. 20. Pushover curve comparisons for CR from $40 \%$ to $70 \%$ using Uniform and Non-Uniform (NU) link distribution for 12-storey structure 
As per design calculations, when CR increases, larger sections are required for the links. This makes them more vulnerable to shear failure rather than flexural damage because as discussed in section 2 , step 4 , larger sections are more susceptible to shear failure. Thus, link sections used in both ZDLD and the newly proposed shear design becomes almost similar after the relevant calculations. The nonlinear analyses of such structural models designed with CRs above their critical limit also indicated the same conclusion as almost all the links yielded in shear prior to any flexure damage.

\subsection{Insight into the seismic behaviour of links and RC wall}

Due to similar qualitative results in all the case studies, only the intermediate height, i.e. the 6-storey structure, is further discussed in details. Shear in the dissipative steel links also highlight expected improvement in their capacity when the design procedure proposed in this work is followed. In each case, i.e., CR $=40 \%$, $60 \%$ with uniform distribution, and $80 \%$ with non-uniform distribution of shear links, the dissipative links are able to redistribute the shear forces in a uniform manner just after the first yield of a steel link which always remains compatible with the undamaged RC wall. Shear in different storey levels of the HCW system are shown in Fig. 21 and 22 for CRs $40 \%$ (with uniform distribution of links), and 80\% (with uniform and non-uniform distribution of links) respectively.

Fig. 23, 24, and 25 represents the evaluation of rotations in the steel shear links for CR 40\%, 60\% (uniform link distribution) and CR 80\% (non-uniform link distribution) respectively. These rotation values are compared to the limits recommended by FEMA 356 [55], Table 5-6 guidelines to verify their suitability for the proposed design procedure. Rotations in the most vulnerable links reach the Immediate Occupancy (IO) level at a displacement of approximately $0.1 \mathrm{~m}$. Drawing reference from the pushover curves illustrated earlier, it is observed that all links are yielded before this displacement. When compared with FEMA 356 [55], Table 5-6, it is also observed that the maximum rotations in each links are well below the Life Safety (LS) limit. For example, the maximum rotation in the links among all the analyses is obtained as $0.016 \mathrm{rad}$ to acceptance limits of $0.005 \mathrm{rad}$ (IO) and $0.11 \mathrm{rad}$ (LS). Also, when compared to AISC 341-16 [56], Clause F.3.4a., it is observed that the maximum rotation in each links stays well below the recommended acceptance limit of $0.08 \mathrm{rad}$. Fig. 26 compares the rotation evaluation in the most vulnerable link (Link 2) for CR 40\%, 60\% (uniform link distribution) and CR 80\% (non-uniform link distribution).

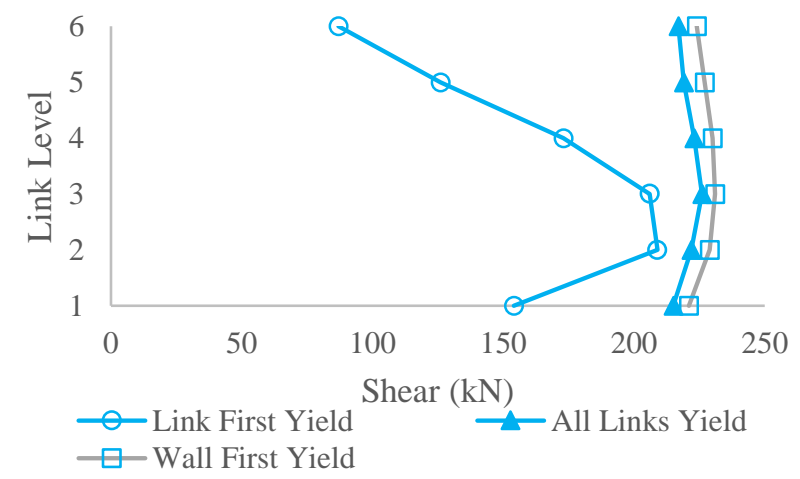

Fig. 21. Shear in the links for CR $40 \%$ with uniform link distribution

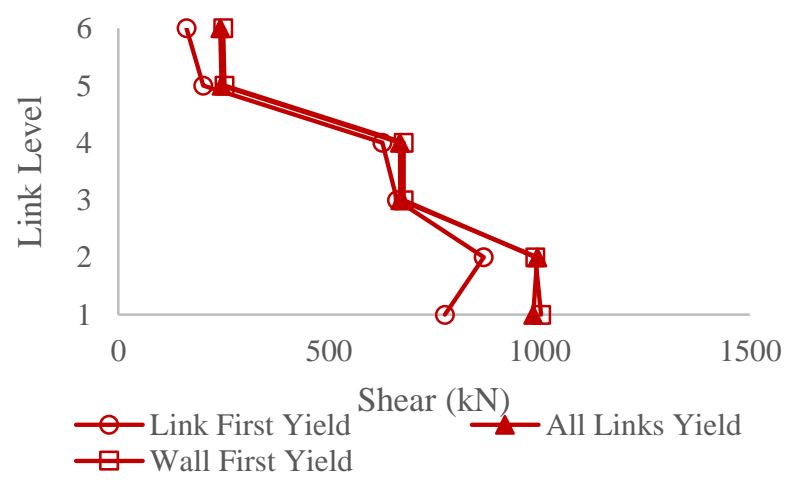

Fig. 22. Shear in the links for CR $80 \%$ with nonuniform link distribution 


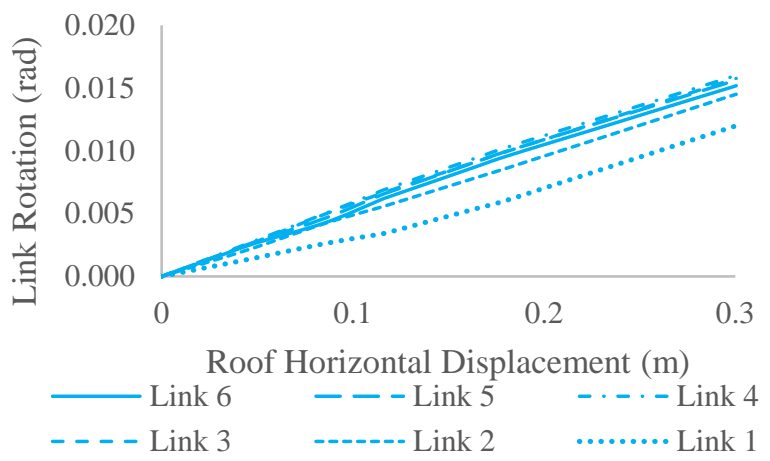

Fig. 23. Rotation evaluation in the links for CR $40 \%$ with uniform link distribution

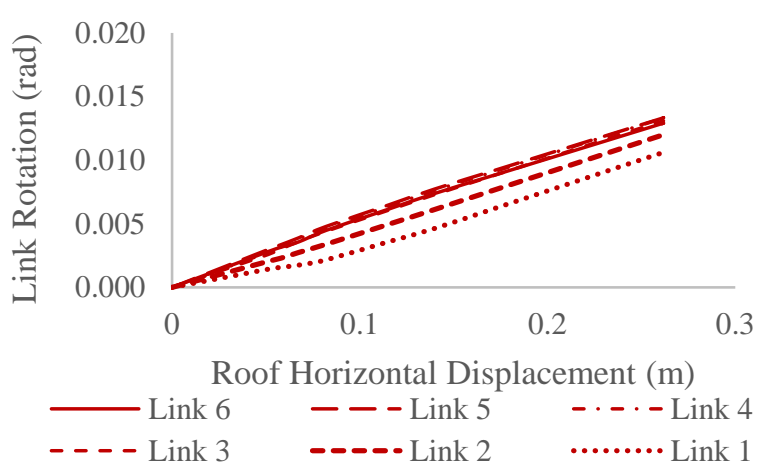

Fig. 25. Rotation evaluation in the links for CR $80 \%$ with non-uniform link distribution

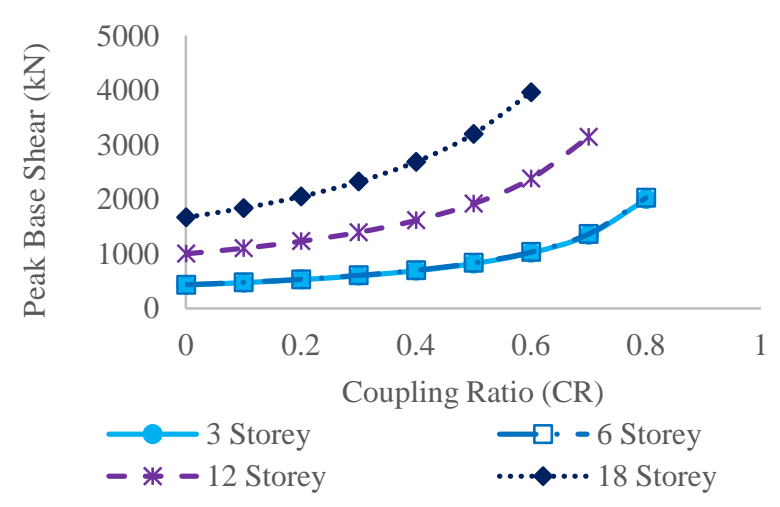

Fig. 27. Peak base shear versus $C R$

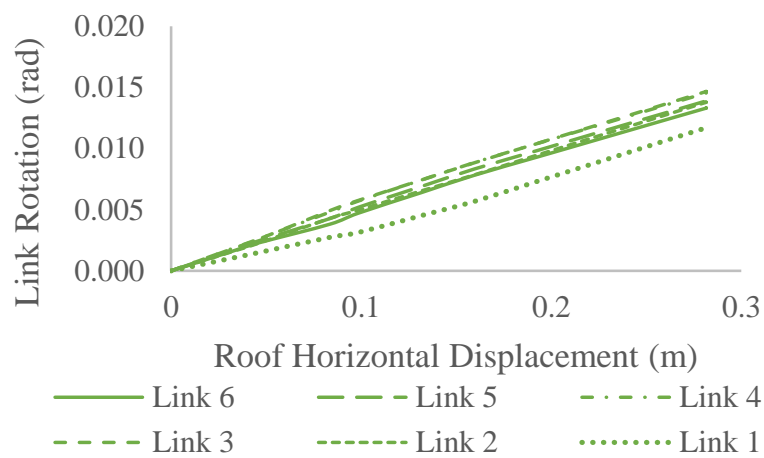

Fig. 24. Rotation evaluation in the links for CR $60 \%$ with uniform link distribution

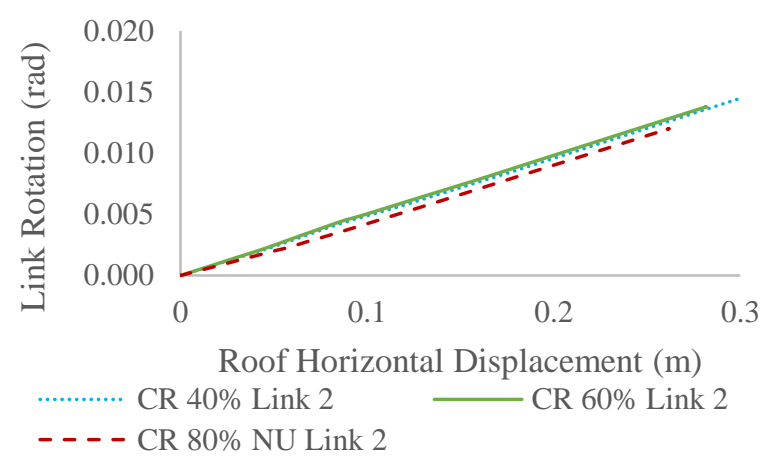

Fig. 26. Comparison of rotation evaluation in Link 2 for CR $40 \%(\mathrm{U}), 60 \%(\mathrm{U})$, and $80 \%(\mathrm{NU})$

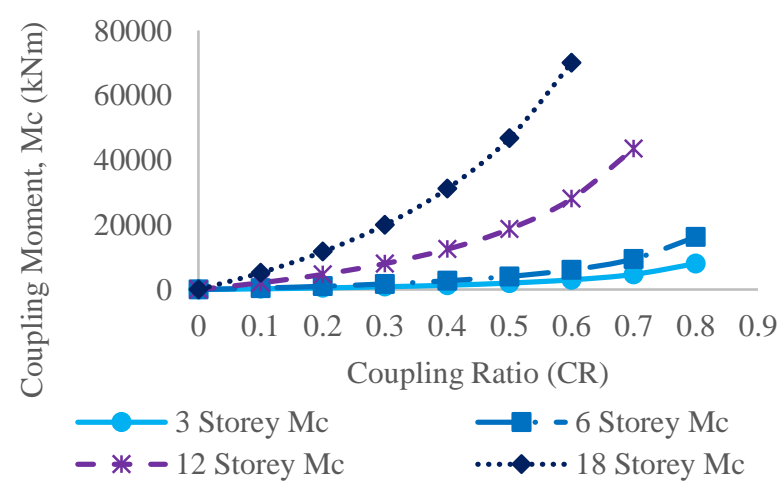

Fig. 28. Coupling moment $\left(M_{c}\right)$ versus $C R$

The variation in peak base shear versus the degree of coupling is shown in Fig. 27 for all the structures. The results indicate a rise in base shear with increase in the CR. As the wall properties are constant for a given no. of storeys, stiffness of the whole structure increases with an increase in CRs and so does the base shear demands. When related to the figures illustrating the bending moments at the bottom of the RC wall, it was also observed that, as CR is 
increased, the wall resists similar moments while the coupling action picks up the additional portion of the seismic overturning moments. The changes in the coupling moment $\left(\mathrm{M}_{\mathrm{c}}\right)$ as a function of $\mathrm{CR}$ for each structure are shown in Fig. 28. As the wall properties for a particular structure are constant, compressive and tensile forces are observed to increase in the right side and left side steel column respectively, thus, increasing the overall coupling moment $\left(\mathrm{M}_{\mathrm{c}}\right)$ of the structure.

As discussed earlier, shear links function primarily as a metallic yielding device (fuse) limiting the maximum lateral force that can be transmitted to the other primary structural members (RC wall and steel columns) and providing significant energy dissipation potential. Tables 12, 13 and 14 present the comparison between the axial forces in the columns for the 3-, 6-, and 12-storey structure respectively, as obtained from the modal pushover analysis at collapse, for the shear critical HCW system as well as the HCW system designed following the ZDLD design approach [28]. In each table, lesser axial forces can be observed in the columns when using the shear critical links. This easily ascertains their ability to limit lateral forces getting transmitted into the other primary structural members and, thus, act as a more efficient energy dissipating device.

Table 12. Axial force $(\mathrm{kN})$ comparisons in side columns obtained from modal pushover analysis on the 3-storey structure at collapse

\begin{tabular}{llllll}
\hline CR & $\mathbf{0 . 4}$ & $\mathbf{0 . 5}$ & $\mathbf{0 . 6}$ & $\mathbf{0 . 7}$ & 0.7 Non-uniform \\
\hline Proposed design & 1182.59 & 1690.42 & 2269.95 & 3046.61 & 3201.64 \\
Zona et al. 2016 [28] & 1206.71 & 1736.64 & 2349.08 & 3460.35 & 3697.23 \\
\hline
\end{tabular}

Table 13. Axial force $(\mathrm{kN})$ comparisons in side columns obtained from modal pushover analysis on the 6-storey structure at collapse

\begin{tabular}{lllll}
\hline CR & $\mathbf{0 . 4}$ & $\mathbf{0 . 6}$ & $\mathbf{0 . 8}$ & 0.8 Non-uniform \\
\hline Proposed design & 1732.90 & 1995.34 & 5467.90 & 5212.90 \\
Zona et al. 2016 [28] & 2103.08 & 2899.46 & 5546.14 & 5622.67 \\
\hline
\end{tabular}

Table 14. Axial force $(\mathrm{kN})$ comparisons in side columns obtained from modal pushover analysis on the 12-storey structure at collapse

\begin{tabular}{lllllll}
\hline CR & $\mathbf{0 . 4}$ & $\mathbf{0 . 5}$ & $\mathbf{0 . 6}$ & $\mathbf{0 . 6}$ Non-uniform & $\mathbf{0 . 7}$ & 0.7 Non-uniform \\
\hline Proposed design & 4056.52 & 5627.05 & 7779.28 & 8416.32 & 13479.00 & 12387.62 \\
Zona et al. 2016 [28] & 4826.82 & 5798.92 & 9396.35 & 9147.98 & 13841.40 & 13213.78 \\
\hline
\end{tabular}

\section{STUDY OF THE SEISMIC BEHAVIOUR THROUGH NONLINEAR INCREMENTAL DYNAMIC ANALYSIS}

According to Eurocode 8, the IDA should be performed for at least seven different accelerograms to evaluate the influence of the record-to-record variability. Eleven different natural accelerograms (TH1 to TH11) as shown in Table 
15, are used as seismic input from databases available in Rexel [57]. Following the current practice, the ground motions are chosen based on magnitude, distance from the nearby fault, and site conditions. These ground motions were recorded at 5-27 km from the closest point of the fault rupture. Moment magnitudes $\left(\mathrm{M}_{\mathrm{w}}\right)$ of these earthquakes vary from 6.4 to 7.1 and these records are from soil locations corresponding to USGS soil class A, B or C. The ground motions are scaled so that the average of their spectral acceleration matches that of the Type 1 Eurocode 8 design spectra for soil type $\mathrm{C}$ at the fundamental vibration period of the structure, and then amplified by the following sequence of factors: $0.33,0.67,1,1.33,1.67,2,2.33,2.67,3,3.33,6.67$, and 10 . The scaled ground motion spectra and their average spectra are illustrated in Fig. 29 along with three Type 1 elastic response spectrum of Eurocode 8 for Soil type C. PGA is considered to be the IM and horizontal roof displacement is taken as the EDP for this current investigation.

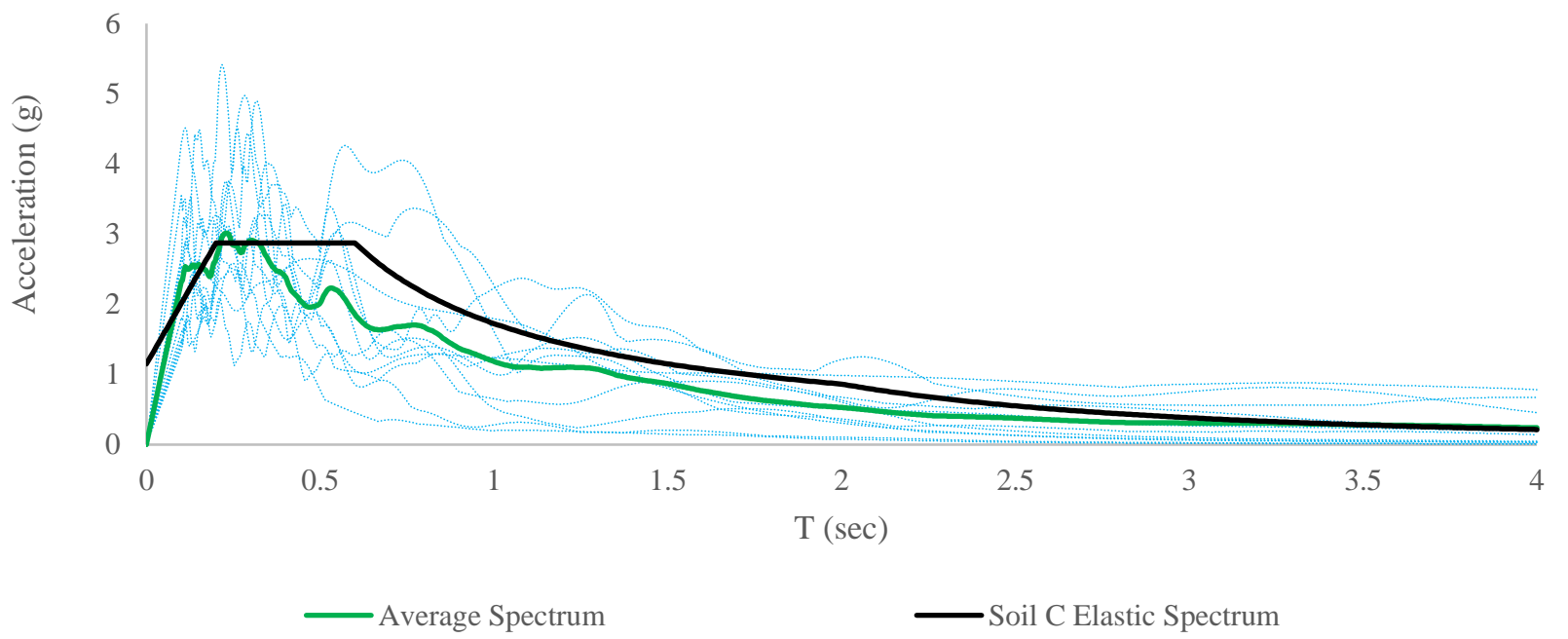

Fig. 29. Natural ground motion spectra with the EC8 elastic response spectrum for soil type A, B and C.

Table 15: Ground Motion records

\begin{tabular}{llccl}
\hline Earthquake ID & Earthquake Name & $\mathbf{M}_{\mathbf{w}}$ & Soil Type & $\mathbf{R}(\mathbf{k m})$ \\
\hline TH1 & Izmit & 7.6 & $\mathrm{C}$ & 20.00 \\
TH2 & Montenegro & 6.9 & $\mathrm{~B}$ & 25.00 \\
TH3 & Erzincan & 6.6 & $\mathrm{~B}$ & 13.00 \\
TH4 & South Iceland & 6.4 & $\mathrm{~A}$ & 5.00 \\
TH5 & Gazli & 6.7 & $\mathrm{C}$ & 11.00 \\
TH6 & South Iceland & 6.5 & $\mathrm{~A}$ & 5.25 \\
TH7 & Darfield & 6.8 & $\mathrm{C}$ & 14.25 \\
TH8 & Imperial Valley & 6.5 & $\mathrm{C}$ & 27.03 \\
TH9 & Loma Prieta & 6.9 & $\mathrm{~B}$ & 7.10 \\
TH10 & Northridge & 6.7 & $\mathrm{C}$ & 20.25 \\
TH11 & Duzce & 7.1 & C & 5.27 \\
\hline
\end{tabular}


The average IDA curve (maximum base shear averaged for each scale factor with its corresponding absolute displacement value) for the eleven natural accelerograms are highlighted in Fig. 30, Fig. 31 and Fig. 32 for CR $40 \%$, $60 \%$ and $80 \%$ (with non-uniform distribution of links) respectively to study their comparison with the relevant static pushover curves as well as the ZDLD design approach [28]. The results from the dynamic analysis are discussed for the 6-storey structure only as the other case studies provided similar qualitative results. The dotted lines represent the IDA curves for each time history considered (as shown in Table 15) and are plotted to give a clear view of the dispersion of the results due to the record-to-record variability.

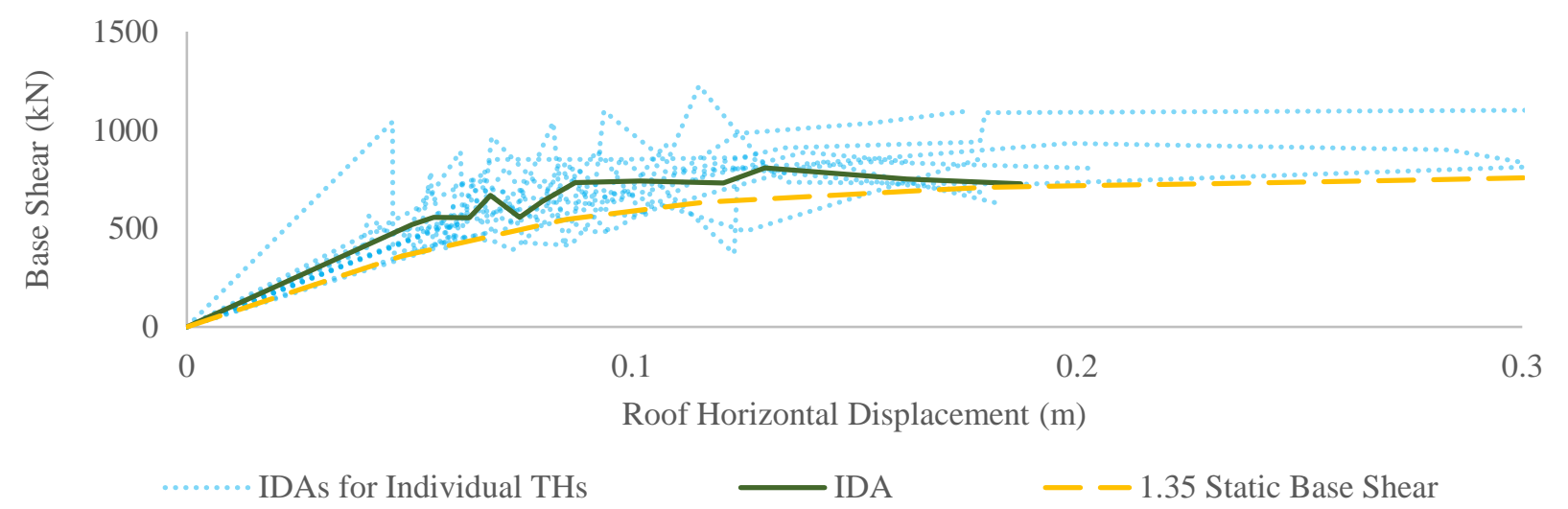

Fig. 30. IDA curves comparison with the static pushover curve for CR $40 \%$ using Uniform link distribution for 6storey structure

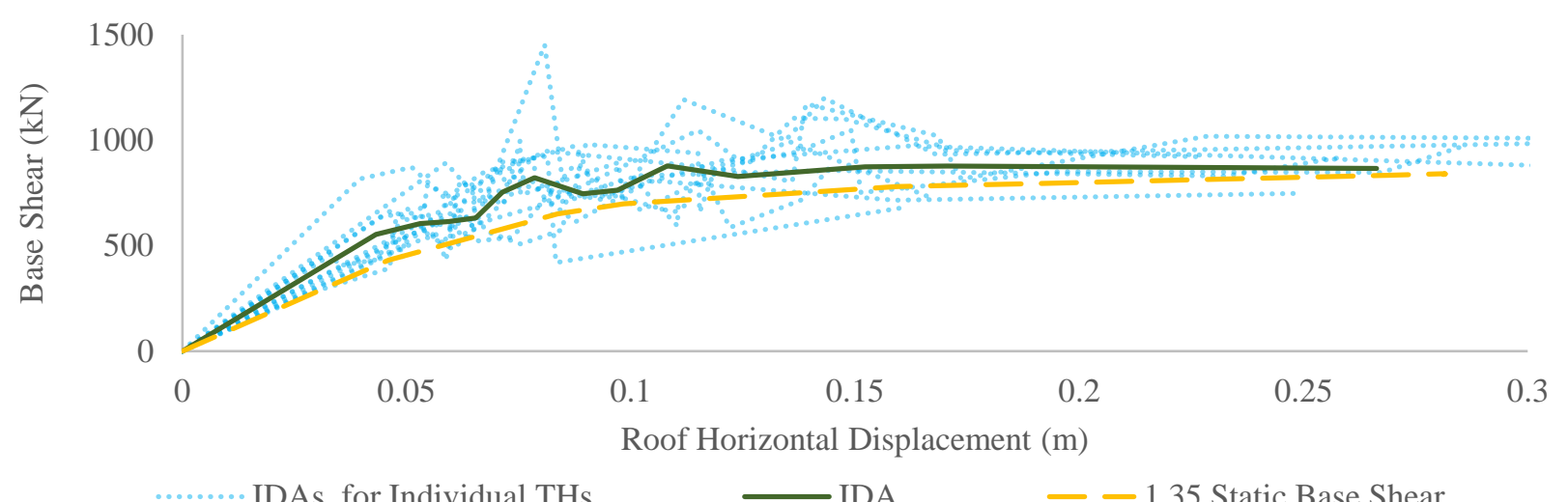

Fig. 31. IDA curves comparison with the static pushover curve for CR $60 \%$ using Uniform link distribution for 6storey structure 


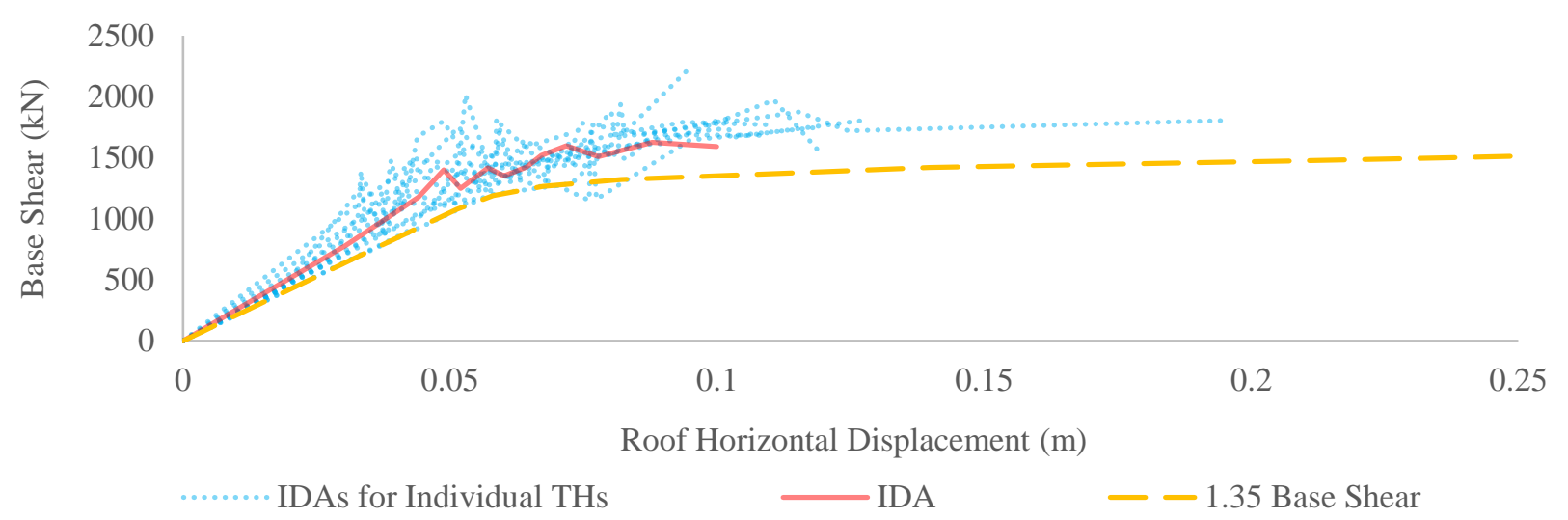

Fig. 32. IDA curves comparison with the static pushover curve for CR $80 \%$ using Non-Uniform link distribution for 6-storey structure

Since a successful application of the designed shear links largely depend on the ability to function most effectively as an energy dissipating device, its dissipation capacity is the primary means of measuring the performance of these links. The area under the hysteresis loop is the amount of energy dissipated by the newly incorporated shear links which are designed following the modified approach. Fig. 33 and 34 illustrates the comparison of hysteretic behaviour between the structures designed following the ZDLD design approach [28] and the shear critical link approach. It is observed that the area enclosed by the curve for the latter case is always greater than that of the previous one, being the shear links dissipating 35\% and 93\% more energy corresponding to the cases in Fig. 33 and 34, respectively. This stands true for all the CRs, low to high, thus proving more efficiency in favour of the shear critical links.
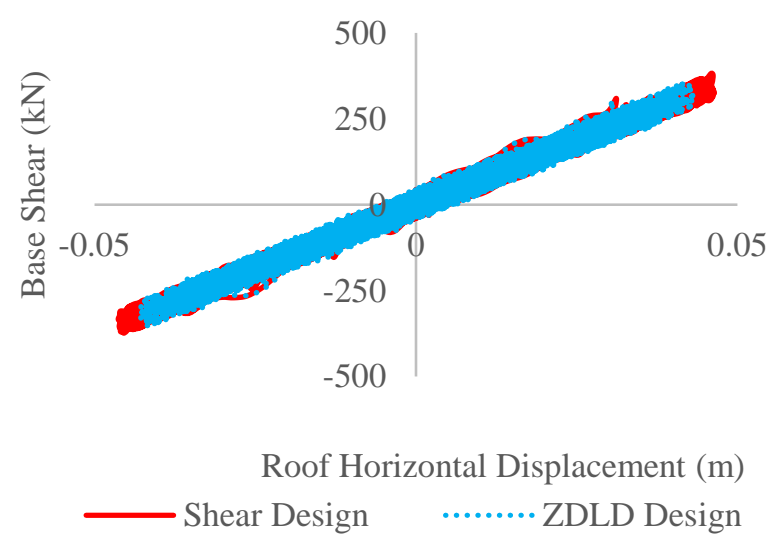

Fig. 33. Comparison between hysteretic loops for CR $40 \%$ using Uniform link distribution and TH7 Time history $(\mathrm{SF}=1)$ for 6-storey structure

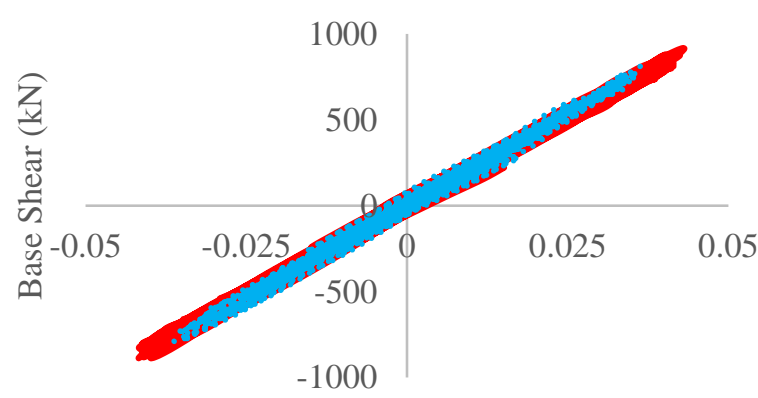

Roof Horizontal Displacement (m)

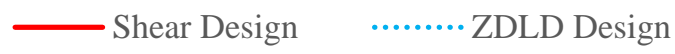

Fig. 34. Comparison between hysteretic loops for CR $80 \%$ using Non-uniform link distribution and TH9 Time history $(\mathrm{SF}=1)$ for 6-storey structure 


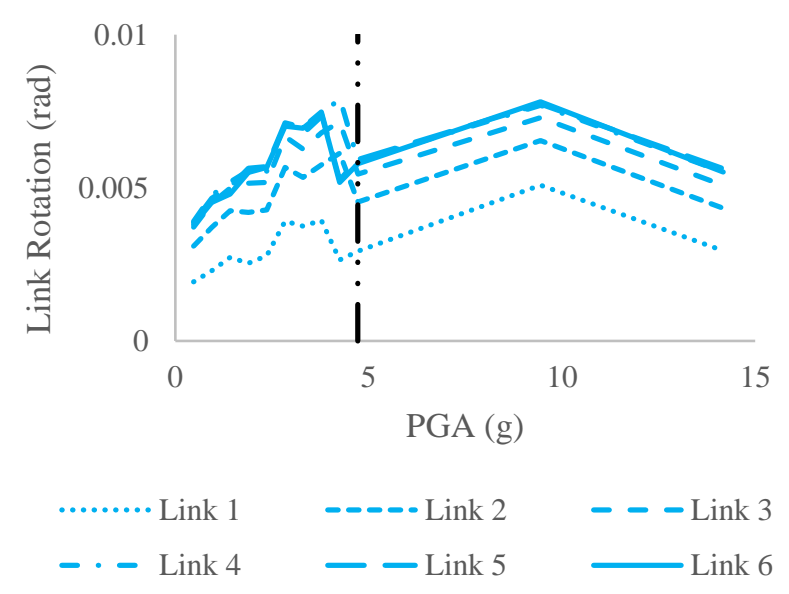

Fig. 35. Dynamic Rotation evaluation in the links for CR $40 \%$ with uniform link distribution

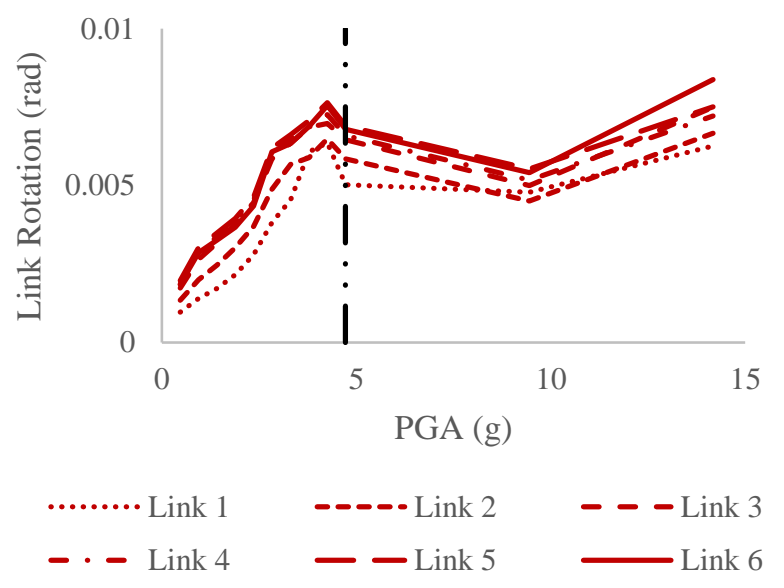

Fig. 36. Dynamic Rotation evaluation in the links for CR $80 \%$ with non-uniform link distribution

Fig. 35 and 36 depict the absolute maximum link rotation evaluation in the shear critical steel links with CR $40 \%$ uniform and CR 80\% non-uniform link distribution respectively. Each line in the plot represents a single link and is determined by averaging the results obtained from all the scaled TH analyses. Table 16 tabulates the absolute average maximum rotation values in the links for the structures with 40\%, 60\% (uniform) and 80\% (non-uniform link distribution) with their corresponding PGA values. These rotation values are also compared to the FEMA 356 [55], Table 5-6 guidelines to verify their suitability for the proposed design procedure. It is observed that the maximum rotation in each link is well below the LS limit (Life Safety) even for a scale factor rising up to 10 corresponding to a maximum PGA of almost 15g. This ensures enough evidence to prove the rotation capacity of the links. However, the vertical dotted line in the figures illustrates the PGA corresponding to reaching the limit state in terms of plastic rotation the RC wall. So the part of the link rotations beyond this limit are practically irrelevant.

Table 16. Maximum dynamic rotation in the shear links for the Natural THs

\begin{tabular}{l|c}
\hline CR with Link distribution & $\begin{array}{c}\text { Max Link Rotation (rad) } \\
\text { (Average from all THs) }\end{array}$ \\
\hline CR 40\% with Uniform Link distribution & 0.0078 \\
CR 60\% with Uniform Link distribution & 0.0080 \\
CR 80\% with Non-Uniform Link distribution & 0.0084 \\
\hline
\end{tabular}

Fig. 37 and 38 report the averaged maximum rotation evaluation comparison between both the ZDLD design and the shear design procedure for $1^{\text {st }}$ floor link (Least vulnerable) and Roof level link (Most vulnerable), considering CRs $40 \%$ (uniform distribution)) and 80\% (non-uniform distribution) respectively. Although notable variations between the previous and the modified design procedure are observed for some of the time history scale factors, the link rotation envelopes (minimum to maximum) are noticed to remain within an approximately similar range for the uniform link 
distributions (Fig. 37). However, the envelope shifted to a comparatively higher value for the non-uniform distributions as shown in Fig. 38. The vertical dotted line in the figures below again represents the limit state of the RC wall.

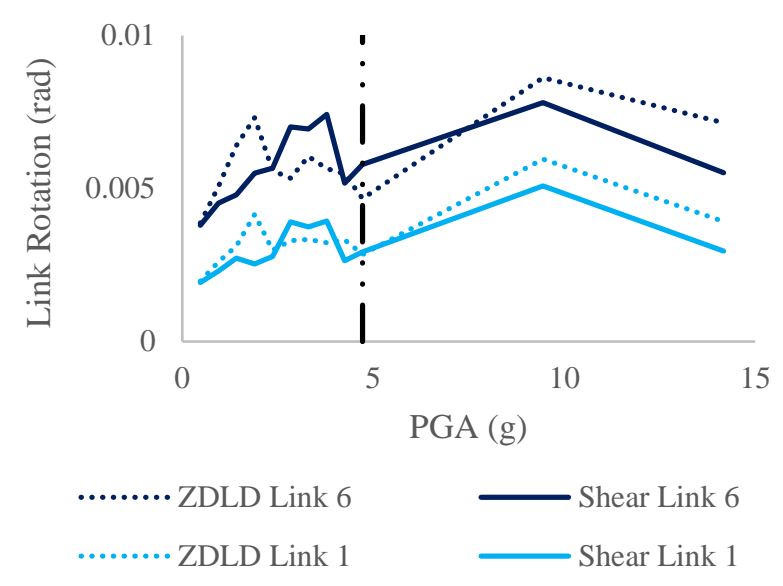

Fig. 37. Dynamic Rotation comparison in links for CR $40 \%$ with uniform link distribution

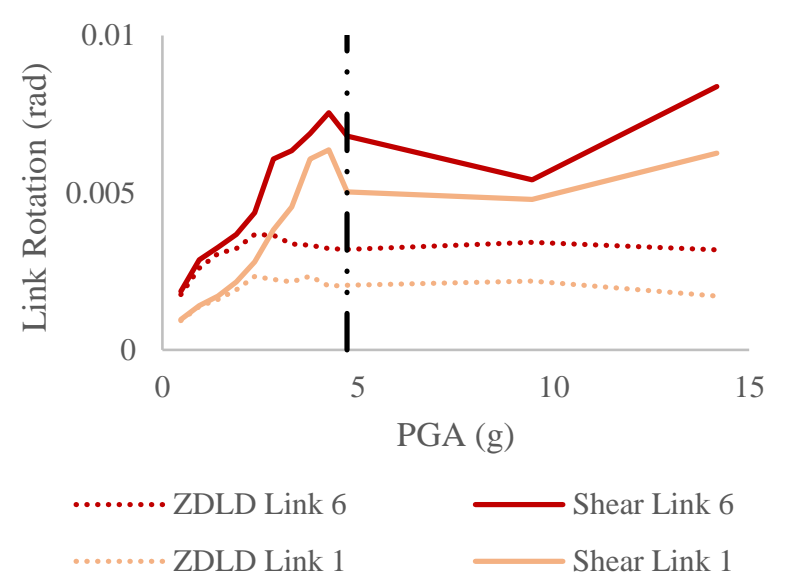

Fig. 38. Dynamic Rotation comparison in links for CR $80 \%$ with non-uniform link distribution

\section{REMARKS AND RECOMMENDATIONS}

Pushover analyses were conducted in accordance with Eurocode 8 prescriptions as two horizontal force distributions were considered, i.e. one with the lateral loads proportional to the first modal deformation and the other with lateral loads proportional to the mass, to include the effect of higher modes in a simplified manner. This procedure validated the anticipated ductility capacity of the proposed innovative HCW system under increasing horizontal loads. To study the HCW systems in a more detailed and comprehensive point of view, nonlinear dynamic analyses with an assigned set of natural time-histories were afterwards carried over to observe the dynamic effects influencing the structural behaviour as well as the record-to-record variability of the seismic response. The finite element models were thoroughly investigated based upon the hysteretic/cyclic behaviour to evaluate their energy dissipation characteristics compared to each other.

The newly proposed improvements over the ZDLD design procedure [28] produced encouraging results as well as fulfilled the design objectives. Some important conclusions were thus drawn from the case studies and therefore, design guidelines are also suggested based on the previously discussed research findings, such as;

- From the comparison between different pushover results for a particular structure, a significant conclusion can be drawn regarding the conservative nature of the EC3 guidelines whereas the EC8 factor of 1.2 for strain hardening does not give rise to any noteworthy variations. So, the proposed design procedure with EC8 guidelines proves to be a suitable method to evaluate such HCW systems.

- Significant decrease in forces in the primary structural members are observed (e.g. axial forces in different levels of steel side columns) when the shear critical steel links are used, thus, establishing their efficient energy dissipation characteristics with an ability to limit the lateral forces getting transmitted into the other 
primary structural members. Hysteretic behaviours obtained from the nonlinear time history analyses also characterizes higher energy dissipation of the shear critical steel links than the intermediate or flexural steel links. This justifies their use to fully optimize the energy dissipation potential of the HCW systems. Furthermore, maximum link rotation values provided strong support towards adequate resistance of the shear links, therefore making it an attractive option to use as coupling elements.

- The "critical limit of CR" for the 6- and 12-storey structure is respectively obtained as $60 \%$ and $50 \%$. Although the case studies on tall (6 and 12-storey) structures seems to show an inverse relation between the critical limit of $\mathrm{CR}$ and the total building height for the tall buildings $(\geq 21 \mathrm{~m})$, the analysis of the 3 -storey structure produces rather unexpected results as the critical limit of CR for this case was obtained as $60 \%$, similar to that of the 6-storey structure. So, after further investigations, it was concluded that the critical limit of CR for all buildings $(\leq 21 \mathrm{~m})$ should be taken as $60 \%$.

- The "ultimate limit of CR" also varies with the building heights. Even after structures are designed with nonuniform distribution of links, ductility targets are not achieved with a CR value greater than $80 \%$ for the 3and 6-storey buildings while the value is $70 \%$ for 12 -storey buildings. However, the desired ductility targets are also observed not to be satisfied for a CR value smaller than $40 \%$ for 3 and 6-storey structure and $30 \%$ for the 12-storey structure (referred to as "lower limit of CR"). Therefore, based upon these findings, a CR value equal to the critical limit with a margin of $10 \%$ is proposed to design the HCW systems.

- Experimental studies on HCW prototypes would provide a further validation of the seismic behaviour of the presented HCW system, including the influence of the constructional variations as well as of the realistic material behaviour. Thus, design, modelling and construction of such prototypes and their calibration based on the experimental outcomes should be considered among the future research needs regarding the presented innovative HCW system. Nevertheless, based upon the discussed results as well as the computational effort, the pushover analyses proved to be a simple and efficient tool to successfully evaluate the deformation capacity of the proposed HCW system compliant with code provisions.

\section{CONCLUSIONS}

The seismic design and behaviour of an innovative hybrid coupled wall ( $\mathrm{HCW}$ ) system consisting of a RC wall coupled via steel links to steel side columns on each side was investigated in this study. The design procedure recently proposed by Zona et al. [28] was refined by a mathematically derived relationship enforcing that the steel coupling links are designed as shear critical dissipative elements. Nonlinear static and dynamic analyses were carried out in order to compare the seismic responses of HCWs designed with the former design procedure and the proposed modified design procedure. It was observed that the HCWs designed with shear critical links attract lesser base shear for a particular displacement value and allows for an overall higher displacement capacity. In addition, forces in the primary structural (e.g. axial forces in different levels of steel side columns) members decrease significantly when the shear critical steel links are used. The design objectives can be fulfilled adopting a uniform link distribution only for a coupling ratio (CR) equal or below a specific value defined in this study as the critical limit of CR. This critical limit of CR for 
uniform link distribution decreases with the increase in the total height of the building. The upper bound of the CR for the non-uniform distribution of links (defined in this work as the ultimate limit of CR) also varies inversely with the building height, but, in a much limited range. Overall, the presented results prove the effectiveness of the shear critical steel links and their efficiency in the considered innovative HCW systems as energy dissipating devices.

\section{REFERENCES}

[1] Paulay T., Priestley M.J.N., Seismic Design of Reinforced Concrete and Masonry Buildings, Wiley, New York, 1992.

[2] Paulay T., (1971), Coupling beams of reinforced concrete shear walls, ASCE Journal of Structural Engineering, 97(3), 843-862.

[3] Paulay T., Santhakumar A.R., (1976), Ductile behaviour of coupled shear walls, ASCE Journal of Structural Engineering, 102(1), 93-108.

[4] Gong B., Harries K.A., Shahrooz B.M., (2000), Behaviour and design of reinforced concrete, steel, and steelconcrete coupling beams, Earthquake Spectra, 16(4), 775-799.

[5] Park W.S., and Yun H.D., (2005), Seismic behaviour of coupling beams in a hybrid coupled shear walls, Journal of Constructional Steel Research, 61(11), 1492-1524.

[6] El-Tawil S., and Deierlein G. G., (2001), Nonlinear analyses of mixed steel-concrete moment frames. Part I - beam-column element formulation. Part II - implementation and verification, ASCE Journal of Structural Engineering, 127(6), 647-665.

[7] El-Tawil S., Kuenzli C. M., and Hassan M., (2002a), Pushover of Hybrid Coupled Walls. Part I: Design and Modelling, ASCE Journal of Structural Engineering, 128(10), 1272-1281.

[8] El-Tawil S., and Kuenzli C. M., (2002b), Pushover of Hybrid Coupled Walls. Part II: Analysis and Behavior, ASCE Journal of Structural Engineering, 128(10), 1282-1289.

[9] Fortney P.J., Shahrooz B.M., and Rassati G.A., (2007a), Large Scale Testing of a Replaceable 'Fuse' Steel Coupling Beam, ASCE Journal of Structural Engineering, 133(12), 1801-1807.

[10] Fortney P.J., Shahrooz B.M., and Rassati G.A., (2007b), Seismic Performance Evaluation of Coupled Core Walls with Concrete and Steel Coupling Beams, Journal of Steel and Composite Structures, August, 7(4), 279-301.

[11] Fortney P.J., Noe S., Rassati G.A., and Shahrooz B.M., (2006a), A Steel-Concrete Composite Solution for Practical Design of Coupling Beams, Steel Structures in Seismic Areas, 2005.

[12] Fortney P.J., The Next Generation of Coupling Beams, Doctoral Dissertation, University of Cincinnati, 2005.

[13] Gong B., and Shahrooz B.M., (2001a), Steel-Concrete Composite Coupling Beams - Behavior and Design, Engineering Structures, 23(11), pp. 1480-1490.

[14] Gong B., and Shahrooz B.M., (2001b), Concrete-Steel Composite Coupling Beams-Part I: Component Testing, ASCE Journal of Structural Engineering, 127(6), 625-631.

[15] Gong B., and Shahrooz B.M., (2001c), Concrete-Steel Composite Coupling Beams-Part II: Subassembly Testing and Design Verification, ASCE Journal of Structural Engineering, 127(6), 632-637.

[16] Gong B., Shahrooz B. M., and Gillum A. J., (1998), Cyclic response of composite coupling beams, ACI Special Publication 174 - Hybrid and Composite Structures, Farmington Hills, MI, 89-112.

[17] Harries K. A., Gong B., and Shahrooz B. M., (2000), Behavior and Design of Reinforced Concrete, Steel, and Steel-Concrete Coupling Beams, Earthquake Spectra, 16(4), 775-799.

[18] Harries K.A., Mitchell D., Cook W.D., and Redwood R.G., (1992), Seismic response of steel beams coupling reinforced concrete walls, ASCE Journal of the Structural Division, 119(12), 3611-3629.

[19] Harries K. A., Mitchell D., Redwood R. G., and Cook W. D. (1998), Nonlinear Seismic Response Predictions of Walls Coupled with Steel and Concrete Beams, Canadian Journal of Civil Engineering, 25(5), 803-818. 
[20] Harries K. A., Mitchell D., Cook W. D., and Redwood R. G. (1993), Seismic Response of Steel Beams Coupling Concrete Walls, ASCE Journal of Structural Engineering, 119(12), 3611-3629.

[21] Shahrooz B. M., Remmetter M. A., and Qin F., (1992), Seismic Response of Composite Coupled Walls, ASCE Composite Construction in Steel and Concrete II, 429-441.

[22] Shahrooz B. M., Remmetter M. E., and Qin F., (1993), Seismic Design and Performance of Composite Coupled Walls, ASCE Journal of Structural Engineering, 119(11), 3291-3309.

[23] Shahrooz B.M., Deason J.T., and Tunc G., (2004a), Outrigger Beam - Wall Connections: Part I Component Testing and Development of Design Model, ASCE Journal of Structural Engineering, 30(2), 253-261.

[24] Shahrooz B.M., Tunc G., and Deason J.T., (2004b), Outrigger Beam - Wall Connections: Part IISubassembly Testing and Further Modeling Enhancements, ASCE Journal of Structural Engineering, 130(2), 262-270.

[25] Shahrooz B.M., Gong B., Tunc G. , and Deason J.D. (2001), An Overview of Reinforced Concrete Core WallSteel Frame Hybrid Structures, Progress in Structural Engineering and Materials, 3(2), 149-158.

[26] Xuan G., and Shahrooz B.M., (2005), Performance Based Design of a 15 Story Reinforced Concrete Coupled Core Wall Structure, Report No. UC-CII 05/03, Cincinnati Infrastructure Institute.

[27] A. Dall'Asta, et al., Innovative Hybrid and Composite Steel-Concrete Structural Solutions for Building in Seismic Area, Final Report, European Commission, 2015. Doi: http://dx.doi.org/10.2777/85404.

[28] Zona A., Degee H., Leoni G., and Dall'Asta A., (2016), Ductile design of innovative steel and concrete hybrid coupled walls. Journal of Constructional Steel Research, 117, 204-213.

[29] Roeder C.W., and Popov E.P., (1978), Eccentrically Braced Steel Frames for Earthquakes, ASCE Journal of the Structural Division, 104(3), 391-412.

[30] Hjelmstad K. D., and Popov E.P., (1983), Seismic Behavior of Active Beam Links in Eccentrically Braced Frames, Report No. UCB/EERC-83/15, Earthquake Engineering Research Center, Berkeley, CA.

[31] Malley J.O., and Popov E.P., (1983), Design Considerations for Shear Links in Eccentrically Brace Frames, Report No. UCB/EERC-83/24, Earthquake Engineering Research Center, Berkeley, CA.

[32] Kasai I., and Popov E.P., (1986), A study of Seismically Resistant Eccentrically Braced Steel Frame Systems, Report No. UCB/EERC-86/01, Earthquake Engineering Research Center, Berkeley, CA.

[33] Kasai K., and Popov E.P., (1986a), General Behavior of WF Steel Shear Link Beams, ASCE Journal of Structural Engineering, 112(2), 362-282, Reston, VA.

[34] Kasai K., and Popov E.P., (1986b), Cyclic Web Buckling Control for Shear Link Beams, ASCE Journal of Structural Engineering, 112(3), 505-521, Reston, VA.

[35] Ricles J., and Popov E. P., (1987b), Dynamic Analysis of Seismically Resistant EBFs, Report No. UCB/EERC87/07, Earthquake Engineering Research Center, Berkeley, CA.

[36] Engelhardt M.D., and Popov E.P., (1989), On Design of Eccentrically Braced Frames, Earthquake Spectra, 5(3), 495-511.

[37] Balendra T., Sam M.T., Liaw C.Y., and Lee S.L., (1991), Preliminary Studies into the Behavior of Knee Braced Frames Subject to Seismic Loading. Engineering Structures, 13(1), 67-74.

[38] Rai D.C., and Wallace B.J., (1998), Aluminum shear-links for enhanced seismic resistance, Earthquake Engineering \& Structural Dynamics, 27(4), 315-342.

[39] Harries K.A., Mitchell D., Cook W.D., and Redwood R.G., (1993), Seismic Response of Steel Beams Coupling Concrete Walls, ASCE Journal of Structural Engineering, 119(12), 3611-3629.

[40] Ghobarah A., and Elfath H.A., (2001), Rehabilitation of a reinforced concrete frame using eccentric steel bracing, Engineering Structures, 23(7), 745-755.

[41] McDaniel C.C., Uang C.M., and Seible F., (2003), Cyclic testing of built-up steel shear links for the new bay bridge, ASCE Journal of Structural Engineering, 129(6), 801-809.

[42] Lim A.K.W., The nonlinear response of reinforced concrete coupling slabs with drop panels in earthquake resisting shear wall structures. MS Thesis, McGill Univ., 1989.

[43] Harries K.A., (2001), Ductility and Deformability of Coupling Beams in Reinforced Concrete Coupled Walls, Earthquake Spectra, 17(3), 457-478. 
[44] El Tawil et al., (2010), Seismic Design of Hybrid Coupled Wall Systems: State of the Art, ASCE Journal of Structural Engineering, July 2010.

[45] Harries K.A., and McNeice D.S., (2006), Performance-Based Design of High-Rise Coupled Wall Systems, The Structural Design of Tall and Special Structures, 15(3), 289-306.

[46] Xuan G., et al. (2008), A performance-based design approach for coupled core wall systems with diagonally reinforced concrete coupling beams, Advances in Structural Engineering, 11(3), 265-280.

[47] Harries K.A., Moulton D., and Clemson R., (2004), Parametric Study of Coupled Wall Behavior Implications for the Design of Coupling Beams, ASCE Journal of Structural Engineering, 130(3), 480-488.

[48] Aktan A.E., and Bertero V.V., (1984), Conceptual seismic design of frame-wall structures. ASCE Journal of Structural Engineering, 110(11), 2778-2797.

[49] Bogdan T., Zona A., Leoni G., Dall'Asta A., Braham C., and Degee H., (2013), Design and Performance of Steel - Concrete Hybrid Coupled Shear Walls in Seismic Conditions, COMPDYN 2013, $4^{\text {th }}$ ECCOMAS Thematic Conference on Computational Methods in Structural Dynamics and Earthquake Engineering, Kos Island, Greece, June 12-14, 2013.

[50] European Committee for Standardization, Eurocode 8: Design of Structures for Earthquake Resistance Part 1: General Rules, Seismic Actions and Rules for Buildings. EN 1998-1, December 2004.

[51] European Committee for Standardization, Eurocode 3: Design of Steel Structures — Part 1-1: General Rules and Rules for Buildings. EN 1993-1-1, May 2005.

[52] Park W.-S., Yun H.-D., (2006), Seismic behaviour and design of steel coupling beams in hybrid coupled shear wall systems, Nuclear Engineering and Design, 236, 2474-2484.

[53] European Committee for Standardization, Eurocode 2: Design of Concrete Structures - Part 1-1: General Rules and Rules for Buildings. EN 1992-1-1, December 2004.

[54] Computers and Structures Inc., SAP2000 V15 Analysis Reference Manual, 2013.

[55] Federal Emergency Management Agency, FEMA-356: Prestandard and Commentary for the Seismic Rehabilitation of Buildings. Fema 356: Prepared by American Society of Civil Engineers, Reston, Virginia, November 2000.

[56] American Institute of Steel Construction, AISC 341-16: Seismic Provisions for Structural Steel Buildings. AISC 341-16: Prepared by American Institute of Steel Construction, Chicago, Illinois, December 2015.

[57] Iervolino I., Galasso C., \& Cosenza E. (2009), REXEL: computer aided record selection for code-based seismic structural analysis, Bulletin of Earthquake Engineering, 8(2), 339-362. doi:10.1007/s10518-0099146-1. 